\title{
Status Report on ASME Code Development for Nonmetallic Core Components in 2020
}

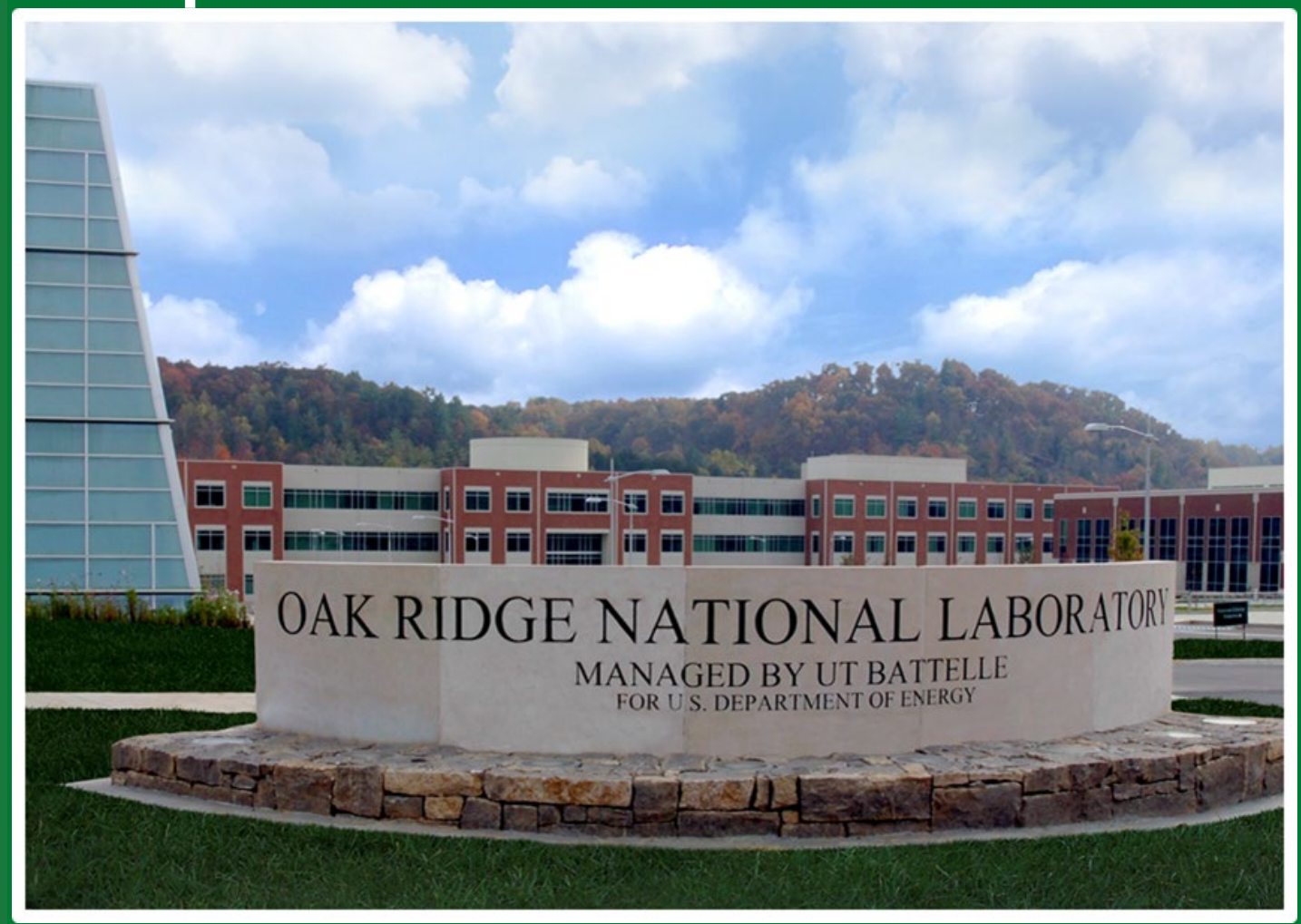

Approved for public release. Distribution is unlimited.
Josina W. Geringer

Timothy D. Burchell

July 2020 


\title{
DOCUMENT AVAILABILITY
}

Reports produced after January 1, 1996, are generally available free via US Department of Energy (DOE) SciTech Connect.

Website www.osti.gov

Reports produced before January 1, 1996, may be purchased by members of the public from the following source:

\author{
National Technical Information Service \\ 5285 Port Royal Road \\ Springfield, VA 22161 \\ Telephone 703-605-6000 (1-800-553-6847) \\ TDD 703-487-4639 \\ Fax 703-605-6900 \\ E-mail info@ntis.gov \\ Website http://classic.ntis.gov/
}

Reports are available to DOE employees, DOE contractors, Energy Technology Data Exchange representatives, and International Nuclear Information System representatives from the following source:

Office of Scientific and Technical Information

PO Box 62

Oak Ridge, TN 37831

Telephone 865-576-8401

Fax 865-576-5728

E-mail reports@osti.gov

Website http://www.osti.gov/contact.html

This report was prepared as an account of work sponsored by an agency of the United States Government. Neither the United States Government nor any agency thereof, nor any of their employees, makes any warranty, express or implied, or assumes any legal liability or responsibility for the accuracy, completeness, or usefulness of any information, apparatus, product, or process disclosed, or represents that its use would not infringe privately owned rights. Reference herein to any specific commercial product, process, or service by trade name, trademark, manufacturer, or otherwise, does not necessarily constitute or imply its endorsement, recommendation, or favoring by the United States Government or any agency thereof. The views and opinions of authors expressed herein do not necessarily state or reflect those of the United States Government or any agency thereof. 
Materials Science and Technology Division

M2AT-20OR030504055

\title{
Status Report on ASME Code Development for Nonmetallic Core Components in 2020
}

\author{
Josina W. Geringer \\ Timothy D. Burchell
}

Date Published: July 2020

\author{
Prepared by \\ OAK RIDGE NATIONAL LABORATORY \\ Oak Ridge, TN 37831-6283 \\ managed by \\ UT-BATTELLE, LLC \\ for the \\ US DEPARTMENT OF ENERGY \\ under contract DE-AC05-00OR22725
}


This page intentionally left blank. 


\section{TABLE OF CONTENTS}

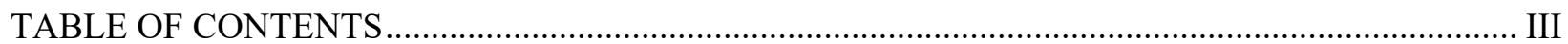

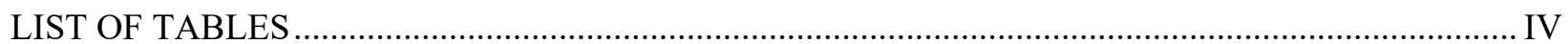

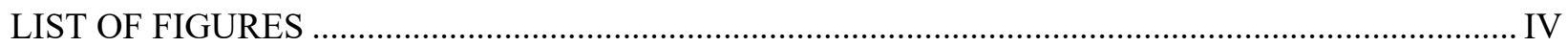

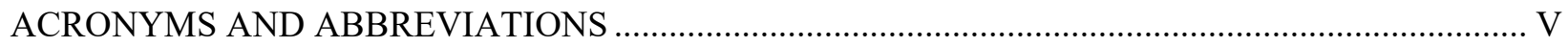

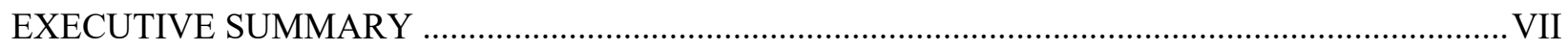

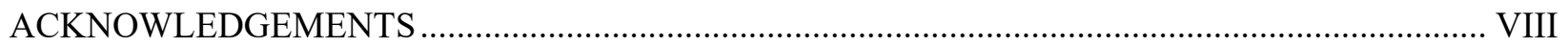

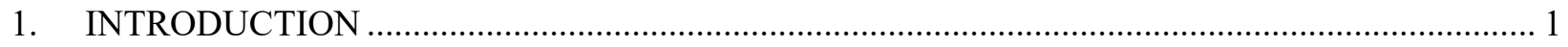

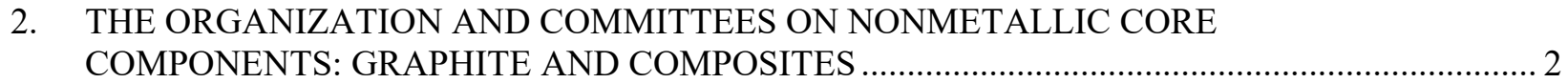

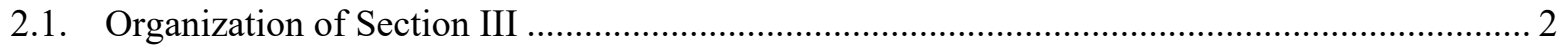

2.2. General Requirements for Graphite and Ceramic Composite Core Components and

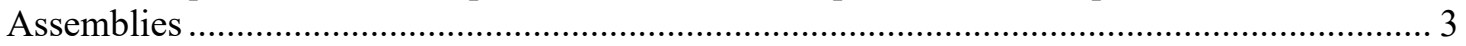

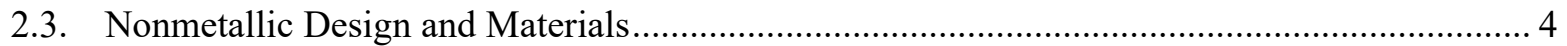

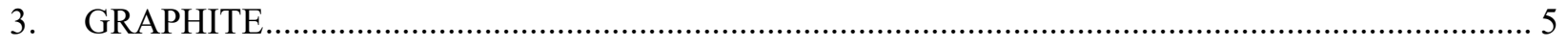

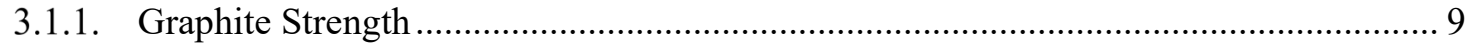

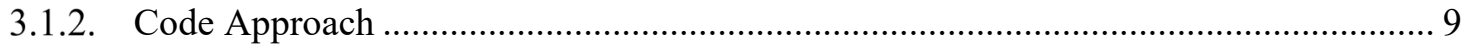

3.1.3. Code Validation of the Full Assessment Method .................................................... 9

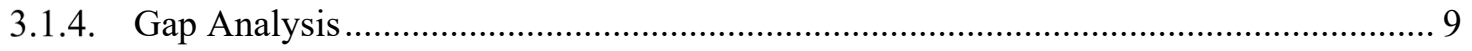

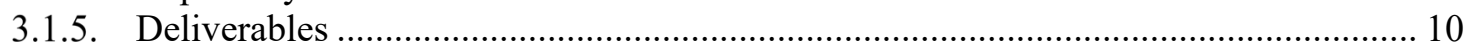

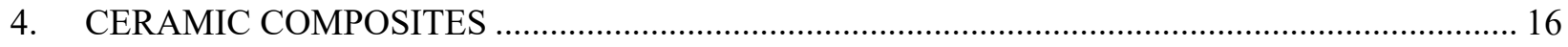

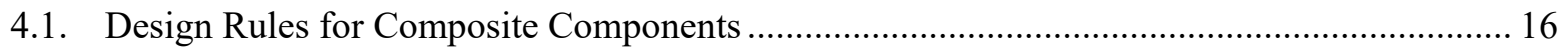

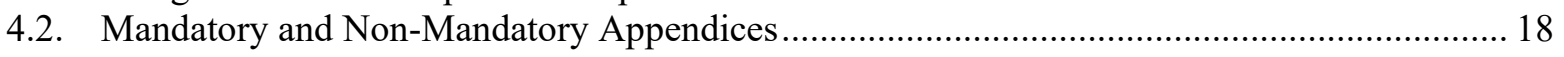

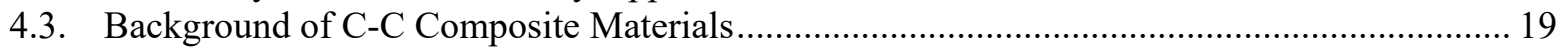

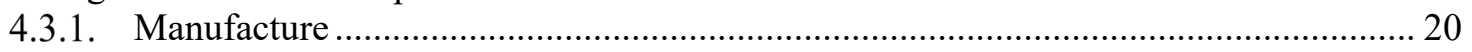

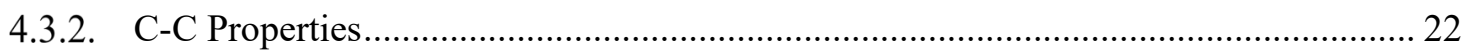

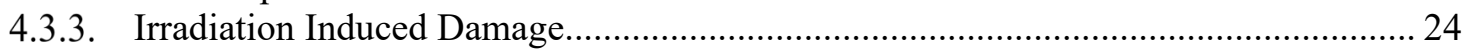

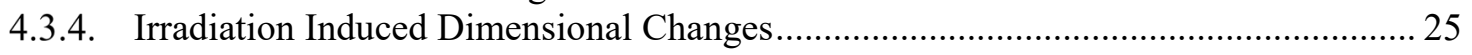

4.3.5. Irradiation Induced Changes in Physical Properties .............................................. 28

4.3.6. Irradiation Induced Changes in Mechanical Properties ............................................. 29

4.3.7. Effects of Chemical Attack/Oxidation on C/C Composites...................................... 29

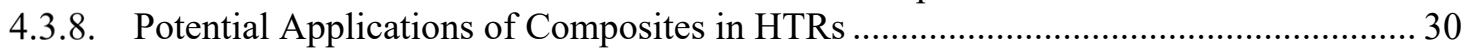

4.4. Composite Materials and NRC assessment review ........................................................... 30

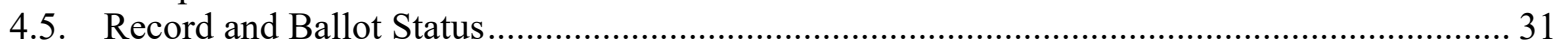

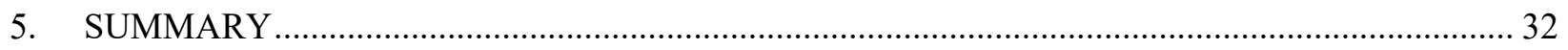

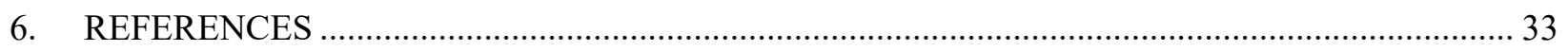

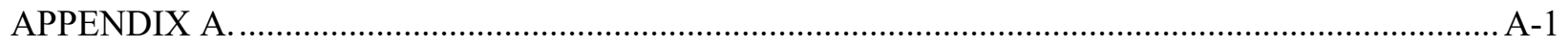




\section{LIST OF TABLES}

Table 1: A comparison of the behavior of steels and nuclear graphite ................................................ 8

Table 2: Existing and proposed $V_{m}$ for ASME Sec III, Div. 5, graphite code (HHA). .......................... 11

Table 3: Design Irradiation Effects for Graphite Core Components (HHA-3142) .................................. 12

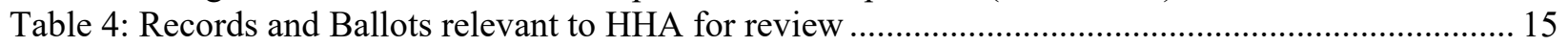

Table 5: Selected properties of several commercially available C-C Composite materials. ......................2 23

Table 6: Mechanical properties of three C-C composites materials - post irradiation comparison ........... 29

Table 7: Records and Ballots relevant to HHB for working group review ............................................. 31

\section{LIST OF FIGURES}

Figure 1. The methodology followed to achieve the objectives for the background manuscript. ................ 6

Figure 2. The methodology followed to achieve the objectives for the gap assessment .......................... 7

Figure 3. Comparison of the behaviors of different fabricated materials from the AGC creep

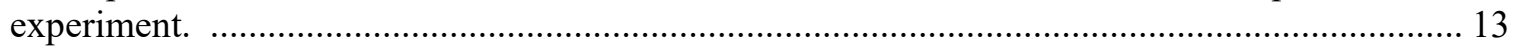

Figure 4. Flow diagram for a typical C-C composite production process ….......................................... 20

Figure 5. The mechanism of radiation damage in the graphite crystal ................................................ 24

Figure 6. Irradiation-induced anisotropic dimension change in a HOPG crystal ....................................25

Figure 7. The core-sheath model of PAN derived carbon fiber structure ..............................................25

Figure 8. Neutron irradiation induced dimensional changes of several C-C composites irradiated

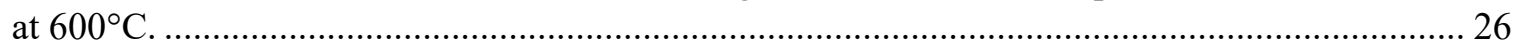

Figure 9. Irradiation dimensional change in two 3D, C-C composites; pitch and PAN fibers ................. 27

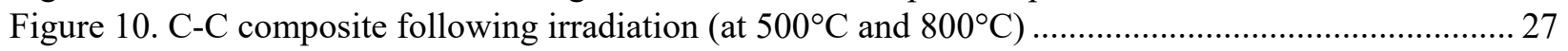

Figure 11. Temperature dependence of thermal conductivity for 3D C-C composites (a) PAN

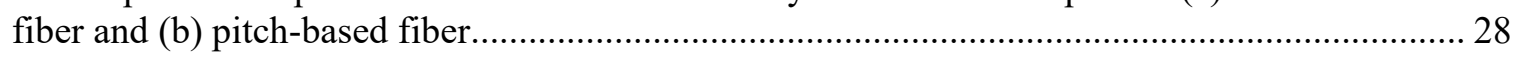

Figure 12. Fractional reduction in thermal conductivity as a function of neutron irradiation.................... 28 


\section{ACRONYMS AND ABBREVIATIONS}

AG

AGC

ANLWR

ASME

ASTM

ATR

BPV

C-C

$\mathrm{CMC}$

CTE

CVI

DOE

DOE-NE

dpa

EPRI

GR GCCCCA

HOPG

HTR

INL

LWR

MDS

MTR

NDM

NRC

NTB

ORNL

POF

$R \& D$

$\mathrm{SC}$

SG-HTR

SiC-SiC

WG against grain

Advanced test reactor Graphite Creep experiment

Advanced Non-Light Water Reactor

American Society of Mechanical Engineers

American Society for Testing and Materials

Advance Test Reactor

Boiler and Pressure Vessel

carbon-carbon

ceramic matrix composites

Coefficient of Thermal Expansion

Chemical Vapor Infiltration

Department of Energy

Department of Energy, Office of Nuclear Energy

displacements per atom

Electric Power Research Institute

General Requirements for Graphite and Ceramic Composites Core

Components and Assemblies

highly oriented pyrolytic graphite

High Temperature Reactor

Idaho National Laboratory

Light Water Reactor

Material Data Sheet

Material Test Reactor

Nonmetallic Design and Materials

Nuclear Regulatory Commission

Nuclear Technical Book

Oak Ridge National Laboratory

Probability of Failure

Research and Development

Subcommittee

Subgroup on High Temperature Reactors

silicon carbide-silicon carbide

with grain 
This page intentionally left blank. 


\section{EXECUTIVE SUMMARY}

The purpose of this report is to provide a status update on the progress and ongoing activities of the current ASME Boiler Pressure Vessel (BPV) Code Section III, Division 5, on nonmetallic core components and assemblies which includes the design rules for graphite and ceramic composite materials. Section III is concerned with the design and construction of nuclear reactor components and Division 5 focuses on high temperature reactors (HTR).

The ASME Section III Committee's function for nuclear items other than pressure-retaining components, is to establish rules of safety related to structural integrity. The term "construction" refers to the all-inclusive effort comprising of materials, design, fabrication, examination, inspection, testing, certification, and pressure relief.

The Department of Energy (DOE) supports industry codes and standards development through focused research providing the technical basis for new or modified codes and standards and the participation of subject matter experts in codes and standards committees.

The activities for the nonmetallic core components and assemblies committees are the pursuit of two working groups that meet quarterly during ASME BPV Code Week meetings. The two working groups are General Requirements for Graphite and Ceramic Composite Core Components and Assemblies (GR GCCCCA) and Nonmetallic Design and Materials (NDM). The rules on general requirements for nonmetallic core components are discussed in the articles of Subsection HA subpart B. Ceramic composites were recently incorporated within the rules, and the GR GCCCCA working group is now in the process of aligning the requirements with the subsections and articles of ASME BPV Code Section III NCA, the general requirements for Division 1 and 2 of the code.

The NDM working group is concerned with the design rules for graphite and composite materials for core components and assemblies discussed in Subsection HH (Class SN Nonmetallic Core Components) subpart A and subpart B which reference graphite and composite materials respectively. The bulk of the progress and work is done within this working group.

A significant undertaking, with discussion that started in 2015, is to gain endorsement of ASME Section III, Division 5, by the U.S. Nuclear Regulatory Commission (NRC). In June 2018, ASME formally recommended endorsement to the NRC. The NRC has since initiated the endorsement review process, which is to be concluded early in 2021. ASME task groups on metallic structures and components, as well as non-metallic core support structures, have been formed to define potential pathways and schedules for NRC endorsement of Division 5. NRC determined to perform a review on the 2017 edition of Section III Division 5 as a baseline. As a result, the use of graphite as nonmetallic core components formed part of the review, but it excluded composite materials (which were first introduced in the 2019 edition).

This report documents progress in FY 2020 directed toward ASME's efforts to develop design codes for graphite and composites. Progress includes a major code review by NRC, the first code enquiry, and its solution, an overhaul of the treatment of Weibull Statistics, and the addition of Nonmandatory Appendices to the composites code relating to carbon-carbon composite materials. 


\section{ACKNOWLEDGEMENTS}

Support for this research was provided by the US Department of Energy, Office of Nuclear Energy (DOENE), Advanced Reactor Technologies program, for the completion of activity milestone M2AT20OR030504055. Oak Ridge National Laboratory is managed by UT-Battelle LLC under contract no. DEAC05-00OR22725 for DOE.

The authors extend their appreciation to Dr. W. Windes, Dr. T.-L. (Sam). Sham, Mr. M.N. Mitchell, Dr.

Steve Gonczy, Dr. M. Jenkins, Dr. Y, Katoh, and Ms. A. Mack and for their input and contributions in special task group efforts. 


\section{INTRODUCTION}

Codes and standards are valuable to both industry and the regulator as they provide criteria, requirements, and/or methods that represent industry best practices. They reduce technical risk for industry, as they can be applied to satisfy regulatory requirements as well as reduces regulatory uncertainty for industry and they guide review processes and enhances review efficiency for the regulator.

The Department of Energy (DOE) supports industry codes and standards development through focused research providing the technical bases for new or modified codes and standards and the participation of subject matter experts on codes and standards committees.

The ASME (Section III: Nuclear) Committee's function is to

establish rules of safety relating to pressure integrity, which govern the Construction of boilers, pressure vessels, transport tanks, and nuclear components, and the in-service inspection of nuclear components and transport tanks. For nuclear items other than pressure-retaining components, the Committee also establishes rules of safety related to structural integrity.

The term "construction" refers to the all-inclusive effort comprising materials, design, fabrication, examination, inspection, testing, certification, and pressure relief. [1]

Activities that support of the review are now in the final phase. This assessment is supported by two manuscripts developed by a task team within the working group. The first focuses on the background and development of the design rules for using graphite materials and why they require different methodologies than have been included in code in the past. The second describes the adequacies and potential areas of optimization that need to be addressed. The first has been submitted to ASME for publication. The second is being finalized and also addresses the input received from the US Nuclear Regulatory Commission (NRC) after external review.

The risks associated with the continuous supply of a select nuclear grade graphite and the lengthy qualification requirements, are driving another optimization effort, which is to investigate potential trends from the material characteristics and forming methods. This will require analysis of irradiated data from various nuclear grades of graphite. From preliminary data, potential trends up to turnaround have been identified. However, this needs to be further investigated and verified. The potential impact of defining trends will be a reduced qualification program and substantial savings in cost and time.

The design and construction rules for composite components and assemblies were published for the first time in the 2019 edition of ASME Boiler and Pressure Vessel Code Sec III, Div 5, under Subsection HH, subpart B. The general requirements are in Subsection HA, subpart B. This was a significant accomplishment after an undertaking of several years (at moderate effort), which was first proposed in 2008.

The general requirements described in Subsection HA subpart B also incorporates rules for composite components as they constitute requirements for the design, construction, examination, and testing of core components and core assemblies used within the reactor pressure vessels of nuclear power plants. The 
articles under Subsection HH subpart B cover materials selection and qualification, composite core component design, machining and installation, examination, testing, and preparation of reports. These articles are supported with information provided in the Mandatory Appendices and Nonmandatory Appendices. The Mandatory Appendices contain requirements that must be followed in construction for components and assemblies described in Subsection HH subpart B. The Nonmandatory Appendices provide additional information or guidance on ceramic matrix composites.

The existing Mandatory Appendices describe details that need to be applied for composites. Within this category, two groups of materials are being considered: carbon-carbon $(\mathrm{C}-\mathrm{C})$ and silicon carbide- silicon carbide ( $\mathrm{SiC}-\mathrm{SiC})$. There are currently no industry-wide materials standards for composites because of their range of composition, fiber architecture, manufacture and properties. For this reason, composite materials are tailored for their intended application. Current descriptions in the Nonmandatory Appendices are largely focused on the properties and behavior of $\mathrm{SiC}-\mathrm{SiC}$ materials.

The current edition of the code is lacking discussion of $\mathrm{C}-\mathrm{C}$ specific properties and behavior as well as the discussion of failure and damage mechanisms. A task team within the Nonmetallic Design and Materials (NDM) working group has started to develop drafts to amend the Nonmandatory Appendices to include C$\mathrm{C}$ specific materials properties and environmental guidance. Some details are discussed in this report.

Additional ongoing task group actions are discussed for both graphite and composites such as the optimization of the Weibull parameters provided in the Mandatory Appendices HHA-II-3000 and HHB-II3000. The optimization efforts include integration with ASTM D7846. Despite the identified application for C-C composites, adequate description is lacking in the code; this is currently being addressed. A next step for the composite design rules is to develop a technical basis document for their application of composites in high temperature reactors (HTRs).

This report discusses the activities for the development of the nonmetallic core components within ASME BPV Code Sec III on nuclear reactor components, Div 5, for HTRs.

\section{THE ORGANIZATION AND COMMITTEES ON NONMETALLIC CORE COMPONENTS: GRAPHITE AND COMPOSITES}

\subsection{ORGANIZATION OF SECTION III}

Users of the BPV Code should refer to the pertinent codes, standards, laws, regulations, or other relevant documents for safety issues other than those relating to pressure integrity and, for nuclear items other than pressure-retaining components, structural integrity.

Section III currently consists of Div 1, Div 2, Div 3, and Div 5. These divisions are broken down into subsections and are designated by capital letters. The first letter " $H$ " indicates the subsection of Div 5 on HTRs.

The current organization of Sec III is as follows:

- Subsection NCA - General Requirements for Division 1 and Division 2

- Appendices

- Division 1 (Rules for construction of nuclear facility components: Subsections NA - NH) 
- Division 2 - Code for Concrete Containments

- Division 3 - Containment Systems for Transportation and Storage of Spent Nuclear Fuel and High-

- Division 5 - High Temperature Reactors

- Subsection HA - General Requirements

Subpart A - Metallic Materials

Subpart B - Graphite and Composite Materials

- Subsection HB - Class A Metallic Pressure Boundary Components

Subpart A - Low Temperature Service

Subpart B - Elevated Temperature Service

- Subsection HC - Class B Metallic Pressure Boundary Components

Subpart A - Low Temperature Service

Subpart B - Elevated Temperature Service

- Subsection HF — Class A and B Metallic Supports

Subpart A — Low Temperature Service

- Subsection HG - Class SM Metallic Core Support Structures

Subpart A — Low Temperature Service

Subpart B - Elevated Temperature Service

- Subsection HH - Class SN Nonmetallic Core Components

Subpart A - Graphite Materials

Subpart B - Composite Materials

The rules on general requirements for graphite and composite materials are discussed in Subsection HA subpart B.

The rules for the design and construction of nonmetallic core components for use in HTRs are discussed in Subsection HH. The rules relevant to graphite materials are discussed in Subpart A and the rules relevant to composite materials are discussed in subpart B under Subsection HH.

\subsection{GENERAL REQUIREMENTS FOR GRAPHITE AND CERAMIC COMPOSITE CORE COMPONENTS AND ASSEMBLIES}

The working group General Requirements for Graphite and Ceramic Composite Core Components and Assemblies (GR GCCCCA) was established in 2018. The purpose of this working group is to develop the requirements for duties, responsibilities, quality assurance, stamping, authorized inspection, and associated mandatory and nonmandatory appendices for all graphite and ceramic composite core components and assemblies. The working group reports to the Subgroup on General Requirements (SG-GR) and to the Committee on Construction of Nuclear Facility Components (BPV III).

This working group is mostly concerned with establishing and maintaining the articles under Sec III Div 5 Subsection HA subpart B. The rules on general requirements for graphite components were first established in 2012. [2] These were then extended to include the requirements for composites materials. The combined rules, for graphite and composites, were published for the first time in the ASME BPV Code 2019 edition.

Another big driver for this group was to ensure that the articles on general requirements for graphite and composite materials align with the changes introduced in Sec III Subsection NCA, the rules on general requirements for Divisions 1 and 2. 
All the of the Div 5 general requirements are in Subsection HA. This arrangement was originally to accommodate the effort to rewrite Subsection NCA. It was envisioned that the general requirements of Division 5 would be incorporated into NCA once the rewriting was completed. [2]

Although the format of Subsection NCA is followed, the uniqueness of graphite and composite materials is addressed. For the process of graphite and composite materials, the designer is responsible to prepare the structural design and produce the design drawings, the construction specification, the design report. The designer must be a GC Certificate Holder.

A GC Certificate Holder may also have other scope such as the design, construction, manufacture of materials, machining of core components and installation of components per certificate description. The GC Certificate Holder can qualify the Material Organization (like material manufacturers, core component manufacturers, Installers, and approved suppliers), while retaining overall responsibility.

According to the rules, the GC Certificate Holders shall comply with the requirements of ASME NQA-1, Quality Assurance Requirements for Nuclear Facility Applications, Part I and, when specifically stated, Part II.5. The duties of the Authorized Nuclear Inspector Supervisor and Authorized Nuclear Inspector are also established in the general requirements.

\subsection{NONMETALLIC DESIGN AND MATERIALS}

The NDM working group was formed in 2019, combining the two previous working groups, Graphite and Composites Design and Graphite and Composite Materials. This was part of the restructuring of the HTR organization that occurred in 2019 within ASME. The purpose of the working group is to establish the rules, standards, and guides for design, material qualification, fabrication, testing, installation, examination, inspection, certification and the preparation of reports for nonmetallic internal components. The latter are defined as components contained within a fission reactor pressure vessel and manufactured from graphite or ceramic matrix composites. The codes, standards, and guides do not apply to nonmetallic fuel matrix materials, fuel compacts, fuel pebbles, bushings, bearings, seals, blanket materials, and instrumentation.

The working group reports to the Subgroup on High Temperature Reactors (SG-HTR) and to the Committee on Construction of Nuclear Facility Components (BPV III).

This working group is mostly concerned with establishing and maintaining the articles under Sec III Div 5 Subsection HH subpart A on graphite materials and subpart B on composite materials. The rules on graphite materials were first established in the 2011 edition of the ASME BPV Code Sec III, Div 5. Its first code case, N-903, concerning the definition of the process zone integration volume, was approved in 2020.

The rules for the design and construction of graphite core components are under NRC review as part of the current assessment activity for the potential endorsement of Sec III Div 5 (2017 edition).

The development of rules for the design and construction of composite core components was initiated in 2008 [3] and were first published in the 2019 edition of the ASME BPV Code Sec. III Div. 5. The rules are defined for ceramic matrix composites including $\mathrm{SiC}-\mathrm{SiC}$ and $\mathrm{C}-\mathrm{C}$. The nonmandatory emphasis is focused on $\mathrm{SiC}-\mathrm{SiC}$ and needs to be expanded to detail information on $\mathrm{C}-\mathrm{C}$. 


\section{GRAPHITE}

\subsection{GRAPHITE MATERIALS AND NRC ASSESSMENT REVIEW}

The NRC's goal is to assess performance needs and issues for materials/component integrity and to support development of a regulatory framework. The approach followed includes evaluating international operating experience, identifying technical issues and resolution, supporting flexible approaches to materials qualification and coordinating with DOE, the Electric Power Research Institute (EPRI), and international counterparts.

The use of consensus-based codes and standards in an advanced reactor regulatory framework can minimize time to completion, provide flexibility in implementation, and enhance regulatory surety. The lack of NRC endorsement of ASME construction rules for advanced non-light water reactors (ANLWRs) represents significant regulatory risk and can delay development and deployment, increase system design and construction costs, and discourage commercial interest.

Discussions regarding endorsement of ASME Sec III, Div 5, began in 2015 and multiple DOE-NRC NonLWR Advanced Reactor Workshops and ASME meetings have followed since then. [4] During June 2018, ASME formally recommended endorsement to the NRC. Since the NRC has initiated the endorsement review process, [6] ASME task groups on metallic structures and components, as well as non-metallic core support structures have been formed to define potential pathways and schedules for NRC endorsement of Div 5. This activity, together with private sector deployment of new advanced reactors, is supported by DOE's Office of Nuclear Energy (DOE-NE). The NRC has been actively participating in task groups as well.

A broad range of advanced reactor vendors and suppliers evoked positive response on the endorsement of the code by the NRC. Endorsement of Div 5 is anticipated to reduce technical risk and support private sector deployment of new advanced reactors. The activity also enjoys support from ASME Sec III, responsible for developing the code, and DOE-NE, which coordinates the industry and the advanced reactor development community. It was decided to use the 2017 ed. [5] of ASME Sect III, Div 5, as a baseline for the review. [6]

ANLWRs include a range of HTR technologies including High Temperature Gas-cooled Reactors, Liquid Metal-cooled Fast Reactors and Molten Salt Reactors. Each reactor technology has both unique and crosscutting high-temperature materials qualification needs, and has different coolants, neutron flux spectra, and operating conditions requiring different structural materials needs. These needs drives technology-specific materials research and development (R\&D). High temperature material ASME Code development provides material qualification standards applicable to multiple HTR technologies which drives ASME Sec III, Div 5, endorsement efforts. [6]

The NRC is now in the process of evaluating ASME Sec III, Div 5 for potential endorsement as Sec I rules are not adequate for advanced reactor design components operating above $425^{\circ} \mathrm{C}$. The review efforts were divided into two task groups focusing on metallic and non-metallic components respectively with the aim to develop a roadmap on ASME actions and schedule to address identified gaps. 
As mentioned, the NRC is tasked to review and address code-relevant issues to enable industry with technology roll-outs that require licensing. Idaho National Laboratory (INL) and Oak Ridge National Laboratory (ORNL) are tasked to support ASME and NRC with their roadmap efforts. The 2017 edition of the ASME BPV Code Sec III, Div 5, on the nonmetallic core support structures section, includes only rules for graphite materials under subsection HH, subpart A. Ceramic composites were first included in the 2019 edition under subsection $\mathrm{HH}$, subpart $\mathrm{B}$, and therefore were excluded from the current endorsement assessment.

Graphite is a material that presents a number of unique design considerations for ANLWRs. Aspects such as graphite properties and degradation need to be considered in the review. Experimental data and operational experience relevant to the performance of graphite as well as the gap on standards, regulatory guidance and test procedures for evaluating graphite properties and degradation.

Because graphite design methodologies differ vastly from those for metals, it was determined that a separate roadmap was needed. The intention of the nonmetallic roadmap is to aid the NRC with its review by providing a summary technical report on the background information (the basis of the nonmetallic rules) and a summary technical report on the potential gap assessment that will focus on whether the current Div 5 Code rules provide reasonable assurance of adequate protection against identified structural failure modes with respect to the argued issues.

The aim and desired objectives of the roadmap are illustrated in the schematics in Figure 1 and Figure 2. The purpose is to provide background that details the code methodology and to explain why the graphite code is different from the metallic codes, and then to address which parts are adequate or requires optimization.

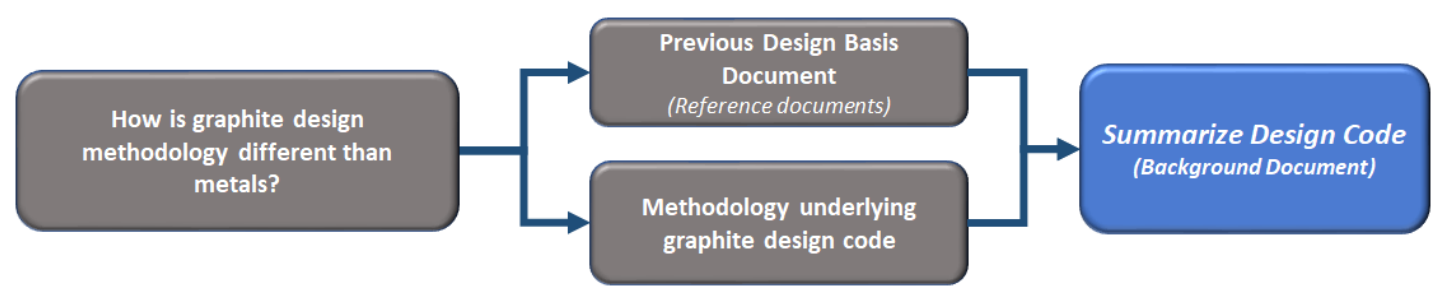

Figure 1. The methodology followed to achieve the objectives for the background manuscript.

A white paper prepared by ORNL was submitted to ASME for publication as a nuclear technical book (NTB). The purpose of the NTB, to be published by ASME Sec III, "Background Information for Addressing Adequacy or Optimization of ASME Section III, Division 5 (2017 ed.) Rules for Nonmetallic Core Components" (Appendix A) is to provide background information on the scope, development and verification of the elevated temperature design and construction rules in ASME Sec III, Div 5, Subsection HH, Class A Nonmetallic Core Support Structures, subpart A Graphite Materials, 2017 ed. 


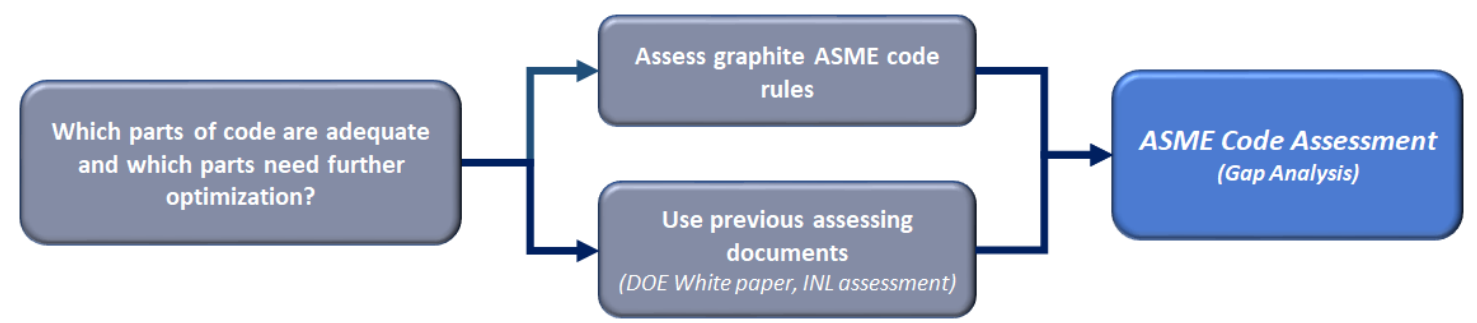

Figure 2. The methodology followed to achieve the objectives for the gap assessment

The NTB to be published by ASME Sec III on the assessment of ASME Section III Division 5 Rules for nonmetallic core components, "Gap Analysis for Addressing Adequacy or Optimization of ASME Section III Division 5 Rules for Graphite Components" is to address adequacy or optimization areas. It discusses concerns where the code lacks guidance or where identified areas need to be optimized or improved. It also highlights where the code is adequate in response to reviewed comments and questions from the NRC.

Similar to the rules for metallic components under Sec III, Div 5, Subsection HH subpart A is structured to provide a central location for all aspects of construction for HTRs nonmetallic components, or more specifically, graphite components. For nonmetallic components according to ASME code terminology, "construction" includes all aspects of Materials (HHA-2000), Design (HHA-3000), Machining, Examination and Testing (HHA-4000), Installation and Examination (HHA-5000), and Nameplates, Stamping and Reports (HHA-8000). The rules stipulate details on material specifications (HHA-I), the requirements of preparing a material data sheet (MDS) (HHA-II) and the requirements for generating design data for different graphite grades (HHA-III). It also gives reference guidance for consideration of factors such as graphite as a structural material (HHA-A) and the environmental and oxidation effects on graphite (HHA-B).

The general requirements compliment the technical rules as they details the rules to classify graphite core components (HAB-2000), the responsibilities and duties during the design and construction process (HAB3000 ), the quality assurance aspects (HAB-4000), the Authorized Inspection requirements (HAB-5000), the applicable standards (HAB-7000), and the required certificates and reports (HAB-8000). They also include a glossary of highlighted terms (HAB-9000).

At the outset, when the code was drafted, several materials issues were considered:

- Differences between nuclear graphite and traditional ferrous core construction metals

- The manufacture of graphite

- $\quad$ Effect of reactor environment on nuclear graphite

Traditionally the construction code did not consider life prediction of materials and changes in properties (due to exposure to environmental and operating conditions), as the emphasis was on construction and the designer needed only to use a margin of safety on short time durability data. Validation of material performance was separately considered through either laboratory testing, prototype performance evaluation, or the assessment of aged materials based on long-time fleet performance, as in the case of light water reactor (LWR) applications. 
For HTRs, a need for a materials database has been identified to address the many gaps in supporting data for long-time effects at high temperatures including time-dependent properties and severe environment service data. Knowledge gaps for metallic materials have been previously reported elsewhere [7,8]. Graphite has a long history of successful use as a core support material in gas-cooled reactors in the United Kingdom, but the time-dependent and service-life effects are very specific to the type of graphite employed. Because of highly vendor-specific and proprietary manufacturing methods, it is not possible to standardize graphite adopting conventional approaches used for metallic materials.

The current code approach under ASME BPV Code Sec III, Div 5, requires that the designer evaluate the material behavior for the specific graphite. The concern with this approach is that the supply chain of a specific graphite is not sustainable for the reactor life, as graphite vendors and their production of nucleargrade graphite are sensitive to market conditions. Lengthy qualification programs are often impractical for HTR vendors because of the risks regarding the promise of graphite supply. If nuclear graphite could be characterized sufficiently to allow designers to predict graphite behavior (e.g., with regard to service effects, as in the case of irradiation until turnaround [a conservative consideration]) based on manufacturing-related characteristics, there is the possibility of more flexibility regarding the use of graphite.

Important differences between the properties and behavior of graphite and steels are summarized in Table 1.

Table 1: A comparison of the behavior of steels and nuclear graphite

\begin{tabular}{|l|l|}
\hline \multicolumn{1}{|c|}{ STEEL (METAL) } & NUCLEAR GRAPHITE (NON-METALLIC) \\
\hline Region of linear elastic behavior & Always non-linear elastic behavior \\
\hline Yield stress can be defined & Yield stress is not definable \\
\hline $\begin{array}{l}\text { High tensile strength, fracture strain and fracture } \\
\text { toughness }\end{array}$ & $\begin{array}{l}\text { Low tensile strength, fracture strain and fracture } \\
\text { toughness }\end{array}$ \\
\hline Small scatter in strength data & Large scatter in strength data \\
\hline Strength decreases with increasing temperature & Strength increases with increasing temperature \\
\hline Relief of peak stress due to plasticity & Relief of peak stress due to micro-cracking \\
\hline Local peak stresses are uncritical & Local peak stresses can cause damage \\
\hline Crack initiation depends upon the primary stress & Crack initiation depends upon the total stress \\
\hline $\begin{array}{l}\text { Material properties are thermal neutron flux } \\
\text { dependent }\end{array}$ & $\begin{array}{l}\text { Material properties are thermal neutron flux } \\
\text { independent }\end{array}$ \\
\hline $\begin{array}{l}\text { Fast neutron flux influences the material } \\
\text { properties (raises the nil ductility temperature) }\end{array}$ & $\begin{array}{l}\text { Fast neutron flux changes all properties and } \\
\text { induces dimensional change and creep }\end{array}$ \\
\hline
\end{tabular}

The probabilistic design approach to nonmetallic component design (Subsection HH subpart A), where strength is statistically defined for the graphite material and an allowable low probability of failure is accepted, is different from deterministic approaches where material strength is nominally determined and component failure is mitigated by the use of a safety factor. 


\subsubsection{Graphite Strength}

Several manufacturing features can be identified which impact the structure and properties of the material:

- Filler particle type and size

- Forming method (extrusion, molding, isostatic pressing)

- Process variables (filler particle type, impregnation type, processing temperatures)

Because of the inherent variability of the graphite flaw structure within the microstructure, the strength is usually described statistically. Several environmental factors also influence the strength of graphite; e.g., graphite strength increases with elevated temperature and with neutron irradiation (up to turnaround) but oxidation results in a loss of strength.

The code places the responsibility of determining the design properties of the graphite on the core designer. The properties are to be listed in the form of a MDS, which is used to justify the design.

\subsubsection{Code Approach}

The design approach allows for three options. Two of these options are analysis methods, the simplified assessment (two-parameter) and full assessment (modified three-parameter). Both are based on probabilistic Weibull analysis, which describes the material reliability, to accommodate graphite material's characteristic billet-to-billet and strength variability. If neither calculation method can be applied, the code allows for a third option to design by test or experimental proof with margins derived from the material reliability curve.

The simplified assessment is semi-probabilistic as it compares the statistical strength values to a simple stress state. The full assessment is also semi-probabilistic, but the probable failure is determined through the evaluation of a statistical strength and the convoluted distribution of the stress in part using Denninghof's modified volume, normalized Weibull weakest link failure criterion approach.

\subsubsection{Code Validation of the Full Assessment Method}

The full assessment method was verified through a variety of component geometries by which failure modes were modelled and compared with experimental test results subjected to similar loading conditions. The study was performed using NBG-18, a nuclear grade medium grain graphite, as a benchmark. The probabilistic failure criteria for the three-parameter methodology, were verified, and it was shown that the failure methodology conservatively predicted real reactor components with larger volume than tensile specimens.

\subsubsection{Gap Analysis}

The code was independently reviewed by Numark Associates, to assess the graphite properties and degradation including source dependency. The objective was to review the available experimental data and operational experience for the performance of graphite and to perform gap analysis on standards, regulatory guidance and test procedures.

The assigned task group is preparing an ASME response to the reviewed comments received. The response emphasizes adequate practices, addresses areas in the code that are already identified and are currently 
being optimized and then discuss areas in which shortcomings are acknowledged and requires optimization but needs experts input for those particular areas.

Areas that may require further optimization include topics on deformation limits, including the definition of the damage tolerance of nuclear grade graphite, and the definition of the modelling methods to describe the material behavior in a non-irradiated and irradiated state when performing internal stress analysis.

\subsubsection{Deliverables}

A significant achievement in support of this work, was production of the manuscript "Background for Addressing Adequacy or Optimization of ASME Section III Division 5 (2017 ed.) Rules for Nonmetallic Core Components".

The "Gap Analysis for Addressing Adequacy or Optimization of ASME Section III Division 5 Rules for Graphite Components" is currently in preparation and will follow.

\subsection{CODE ACCOMPLISHMENT: THE VOLUME INTEGRATION RULE}

At first publication, Subsection HH Nonmetallic Core Components, subpart A Graphite Materials, established the rules for the use of graphite in gas cooled reactors. It used NBG-18, a medium grain graphite, to verify the code basis. NBG-18 was selected for the South African Pebble Bed Modular Reactor (PBMR), a driver for the code establishment at the time.

In Sec III, Div 5, the article on design, HHA-3000, specifies how to determine the probability of failure (POF) by using the process volume, $V_{m}$, which is currently described as the cube of 10 times the maximum grain size (based upon the anticipated use of a medium grained graphite). This parameter is used when defining the finite element model mesh size.

In the past, it has been demonstrated that this is an effective method for graphite with a grain size of $1.6 \mathrm{~mm}$, like NBG-18. [9]. However, compared with fine-grain graphite such as IG-110 and NG-CT-10, previously identified $[10,11]$, the code approach is ultra-conservative on its calculations when only grain size is used to define the process zone volume $\left(V_{m}\right)$ size.

The ultra-conservatism was first raised when the full assessment method, based on a three parameterWeibull weakest link approach, was adopted after it had demonstrated an acceptable conservatism for medium grain graphite such as NBG-18.

For example (from Table 2), the maximum grain size for NBG-18 is $1.6 \mathrm{~mm}$; therefore, the cube of ten times the grain size, the process volume, is $4096 \mathrm{~mm}^{3}$. For IG-110 the maximum grain size is $0.020 \mathrm{~mm}$, and similarly the process volume is $0.008 \mathrm{~mm}^{3}$. The difference in $V_{m}$ between the two graphite grades is $10^{6}$, which is overly conservative, placing a computational analysis burden on graphite with smaller grain sizes.

A method that uses a process zone (PZ) volume was proposed. More detail and background on the validity of the proposed change as it relates to graphite properties, component geometry, and stress gradients is 
provided in ref. [11]. Table 2 shows the implication or suggested changes of the rule for different graphite grades. Equation (1) shows how the process zone size, $r_{c}$, is calculated. $K_{I C}$ is the critical stress intensity factor $(\mathrm{MPa} \sqrt{\mathrm{m}})$ and $\sigma_{t}$ is the tensile strength $(\mathrm{MPa})$ and Equation (2) shows how the process zone volume is calculated.

$$
\begin{gathered}
r_{c}=\frac{1}{2 \pi}\left[\frac{K_{I_{C}}}{\sigma_{t}}\right]^{2} \\
\text { Proposed } V_{m}=\frac{4 \pi}{3} r_{c}{ }^{3}
\end{gathered}
$$

Table 2: Existing and proposed $V_{m}$ for ASME Sec III, Div. 5, graphite code (HHA). [11]

\begin{tabular}{|l|c|c|c|c|}
\hline & \multicolumn{2}{|c|}{ Existing ASME Rule } & \multicolumn{2}{c|}{ Proposed New Rule } \\
\hline GRADE: & Grain size & Vm & PZ size, rc & Proposed Vm \\
\hline \multicolumn{1}{|c|}{ units } & $\mathbf{m m}$ & $\mathbf{m m}^{\mathbf{3}}$ & $\mathbf{m m}$ & $\mathbf{m m}^{\mathbf{3}}$ \\
\hline NBG-18 (WG) & 1.6 & 4096 & 6.6 & 1198.8 \\
\hline NBG-18 (AG) & 1.6 & 4096 & 7.8 & 1995.5 \\
\hline PCEA (WG) & 0.8 & 512 & 10.8 & 5335.5 \\
\hline PCEA (AG) & 0.8 & 512 & 8.6 & 2664.3 \\
\hline IG-110 & 0.02 & 0.008 & 3.0 & 113.1 \\
\hline $\mathbf{2 1 1 4}$ & 0.013 & 0.0022 & 1.7 & 21.7 \\
\hline
\end{tabular}

An independent validation calculation [12] was performed to compare the results of the current failure methodology using grain size vs a revised methodology using the $\mathrm{PZ}$ as a volume size. It was determined that the PZ method did show an improvement when stress analysis results were compared.

The change was proposed through two ASME records, 16-2113 and 16-2114, created to review the proposal as a code change and a code case respectively, and submitted for ballot review to the applicable ASME subcommittees.

The first graphite code case, N-903, and the revised code section were approved and adopted by the ASME BPV Code on March 2020. The adoption will be included in the 2021 edition of the ASME BPV Code Sec III, Div 5, the design and construction rules for nuclear components of high temperature reactors.

\subsection{IDENTIFIED CHALLENGES, OPTIMIZATION NEEDS AND ACTIONS}

It was previously determined [13] that the most significant phenomena in graphite associated with aging in a 60-year lifetime (for some core components) included irradiation effects on material properties (such as dimensional changes and low temperature net heat capacity) and the consistency of graphite quality and performance over the service life.

Theories explaining graphite behavior have been postulated and shown to represent experimental data well; however, the theoretical models still need to be validated with new-generation graphite, as material 
performance is very specific to the selected nuclear-grade graphite. They also need to be extended to higher neutron doses and temperatures pertinent to HTR concepts. Recent and current graphite irradiation experiments (e.g., the AGC series) will provide the data needed to validate many of the currently accepted models, as well as provide the needed data for design confirmation.

The objective for the Advanced Test Reactor (ATR) graphite creep (AGC) irradiation experiments was to provide key irradiation data, such as [14]

- Irradiation creep design data and data on the effects of irradiation creep on key physical properties (e.g., strength, elastic modulus, coefficient of thermal expansion [CTE])

- The effects of neutron irradiation on the properties of a wide range of relevant nuclear graphites, including dimensional changes, strength, elastic modulus, thermal conductivity, and CTE

- Data on the single-crystal irradiation behavior of graphites to be derived from highly oriented pyrolytic graphite (HOPG)

These data are critical to the design licensing of HTR graphite components and support model development work, including irradiation effects models such as dimensional change and creep strain, structural modeling, and fracture modeling. This effort was performed to underpin the code requirements specified in HHA2220 for irradiated materials properties. Those requirements are supported with data that need to be generated in the MDS specified under Mandatory Appendix HHA-II.

The magnitude of the material property change in a particular graphite depends on the damage dose and irradiation temperature. According to the code, HHA-2131, the damage dose and temperature range for the measurements shall cover the qualification envelope range of the reactor in design, or as required in the application of the graphite grade in the graphite core assembly. HHA-3142 discusses the limitation and conditions to evaluate the irradiation effects of graphite. The conditions are summarized in Table 3.

In Mandatory Appendix HHA-III-3300 the code limits the measured temperature-dependent properties to a maximum of $200^{\circ} \mathrm{C}$ temperature increments. It allows test measurement to occur at a temperature below the maximum use temperature because of the necessity to retain, rather than anneal, radiation damage. Moreover, only if the designer desires to take account of the strength increase at low or intermediate damage (from irradiation) shall the irradiation-induced change in strength be measured.

Table 3: Design Irradiation Effects for Graphite Core Components (HHA-3142)

\begin{tabular}{|c|c|l|}
\hline $\begin{array}{c}\text { Dose Limit } \\
\text { (DPA) }\end{array}$ & Condition & \multicolumn{1}{|c|}{ Design analysis requirement } \\
\hline$<0.001$ & Unirradiated & Simplified \\
\hline$>0.001$ & Irradiated & $\begin{array}{l}\text { Effect on thermal conductivity shall be considered } \\
\text { (thermal stress and stress gradients) }\end{array}$ \\
\hline$>0.25$ & Irradiated & $\begin{array}{l}\text { Full viscoelastic analysis. } \\
\text { Full effects of neutron irradiation (HHA-2220) }\end{array}$ \\
\hline
\end{tabular}

Several irradiation experiments have been performed in material test reactors (MTRs), and a significant amount of data has been accumulated through the Generation IV materials effort. As a result, a large 
database on irradiated graphite properties for several graphite grades is available to the HTR community. However, because of the complex nature of graphite material - the structure and properties of which rely on the geological availability of coke and binder or raw materials, and a continuous supply thereof - it is to be expected that there will be a continuous future need to qualify new grades of graphite as the raw materials constantly change. The designer's risk, due to material changes, is that it may be necessary to periodically reapprove graphite materials.

The concern with this approach is that pursuing a graphite qualification program could take years and is costly owing to the typical size of the undertaking (the number of types and physical sizes of the specimens required to measure different properties at various temperature and dose conditions). This problem is further exacerbated by the limited capacity of the currently available MTRs.

An alternative approach is to evaluate already generated irradiated material properties, for common response in the fabrication parameters (i.e. grain size, density, and fabrication method as illustrated in Figure 3 [15] (data points extracted from AGC-1 and AGC-2 reports). If trends can be derived to predict material behavior, and can be used in the code, these may enable the designer to select materials at lower risk without pursuing a full qualification program. However, implementing such rules requires demonstrating that all grades (within the defined parameters) have similar responses such as strength, CTE, density and thermal conductivity. Moreover, similar responses for dimensional change and creep also need to be demonstrated.

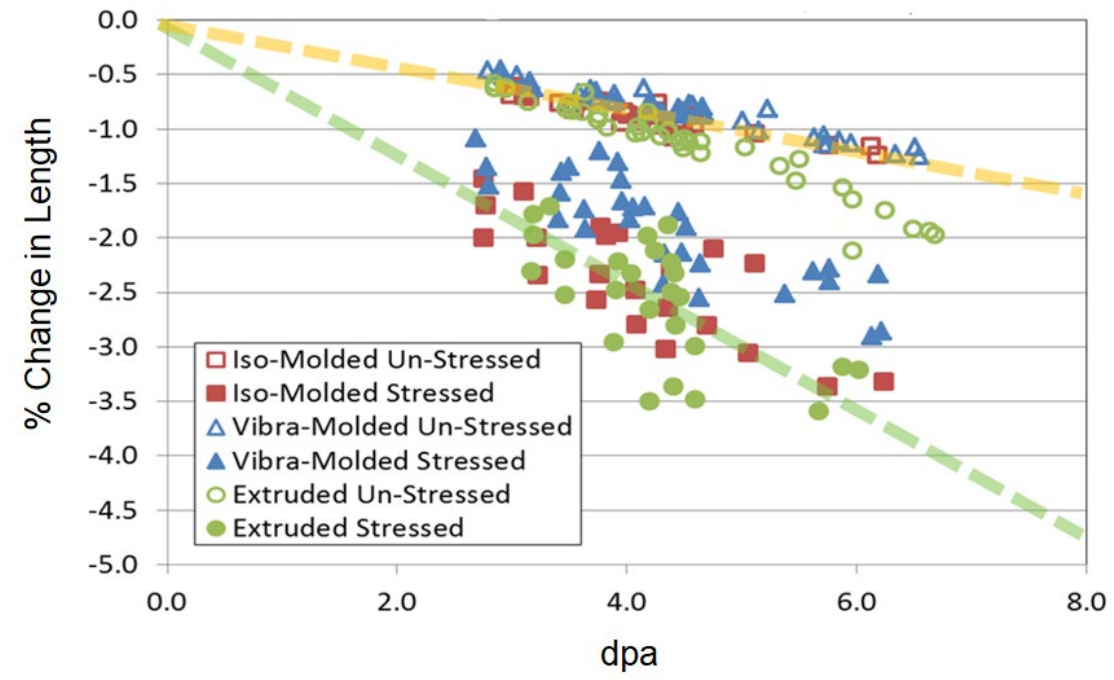

\section{Figure 3. Comparison of the behaviors of different fabricated materials from the AGC creep experiment. [15]}

Based on preliminary analysis of existing data, it seems that these trends can be determined for materials up to turnaround point. However, material behavior becomes more unpredictable after turnaround, increasing the uncertainty of the material performance. 
Further demonstration will be required to show that the code retains its conservatism. A new grade must not have a lower POF than the currently defined limits. The designer or applicant may still need to have to do some irradiation testing to demonstrate that the new grade behaves according to the predicted model.

A future working group action will be to appoint a new task group that will evaluate the irradiation data and recommend the necessary steps for inclusion of these methods within the code. Decisions on how to group the data, or how to include (or reference) the data within the code, and any appropriate modifications to the code text, will be assigned to this task group.

Another activity or current optimization effort is to revise the allowable stress calculation methods stipulated under the Mandatory Appendix HHA-II-3300 using the two-parameter Weibull analysis defined in HHA-II-3100. The code requires that

...one obtains estimated values of $m^{*}$ (Weibull modulus) and $S_{c}^{*}$ (characteristic strength) from the measured values (strength values) for the true Weibull parameters $m$ and $S_{c}$. These estimated values are approximations whose precision depends on the scope of test samples examined. In the stress evaluation, the Weibull parameters corresponding to a confidence level $(\gamma)$ of $95 \%$ are to be used (lower limit of the one-sided confidence interval). [16]

The modulus at the lower limit, $m_{95 \%}$, and the characteristic strength at the lower limit, $S_{c 95 \%}$, are to be determined using functions with correction factors derived from graphs given in HHA-II-3100-1 and HHAII-3100-2 [16]. The former specifies the correction factor of the shape parameter (at the $95 \%$ confidence interval), and the latter specifies the correction factor of the characteristic value (at the $95 \%$ confidence interval). The allowable stress value, $S_{g}$, is then derived using the POF and the determined parameters using Equation (3), which is given in HHA-II-3300 [16]:

$$
S_{g}=S_{C 95 \%}[-\ln (1-P O F)]^{\frac{1}{m_{95 \%}}}
$$

Comparing the previously discussed approach with the method reported in ASTM D7846 (Standard Practice for Reporting Uniaxial Strength Data and Estimating Weibull Distribution Parameters for Advanced Graphites) [17], there are some discrepancies in the nomenclature and terminology used for the Weibull parameters in discussing confidence bounds. It has been suggested that the code figures HHA-II3100-1 and HHA-II-3100-2 be replaced with the pivotal quantity functions that align with the ASTM D7846 approach.

Both the Mandatory Appendices in the graphite code under subsection HHA, and the ceramic composites code under section HHB will benefit from the proposed revision, to be recorded in ASME record 20-1308. A task group is currently assigned to address inconsistencies and optimize the application to maintain consistency between ASME and ASTM.

\subsection{ONGOING ACTIONS}

In the 2019 edition of the ASME BPV Code Sec III, Div 5, in subsection HH subpart A, it was determined that the code needs additional optimization with regard to strength testing and the use of terminology describing the damage in graphite due to irradiation. 
The MDS listed in mandatory articles from subsection HHA-II-2000 gives the impression that graphite strength tests shall be conducted at elevated temperature intervals to obtain temperature dependence values. However, it omits stating that the elevated temperature measurement is only necessary, should the designer want to take credit for the gain in strength due to the elevated temperature condition. A unique characteristic of graphite material is that its strength increases with increasing temperature (unlike other materials). Therefore, the conservative approach is to measure graphite at ambient or low temperature which is a relatively quick and easy test. The change is being proposed in ASME record 19-2806.

Because of variations in energy spectrum from reactor to reactor and the definition associated with the fast spectrum, it was determined to remove fluence references in the text and instead use only the damage dose exposure unit measured in displacements per atom (dpa). This is a fundamental parameter for evaluating radiation damage. It represents the average number of atoms in a unit volume being displaced from their normal lattice site as a result of energetic particle bombardment. Transmutation effects due to thermal neutron interaction are negligible for graphite materials. The code change is proposed in ASME record 192805.

A modification (ASME record 19-1306) is being prepared to address reactor coolant specific conditions on abrasion and erosion, which is currently specified for gas cooled reactors only.

\subsection{BALLOT STATUS}

Table 4 summarize the current status of Sec III approved and subcommittee (SC) and working group NDM review activities:

Table 4: Records and Ballots relevant to HHA for review

\begin{tabular}{|c|c|c|c|}
\hline \#Record & $\begin{array}{l}\text { Last } \\
\text { \#Ballot }\end{array}$ & Purpose & Status \\
\hline $16-2113$ & $20-957$ & Modification of HHA-3217 for fine grained graphite. & Approved \\
\hline $16-2114$ & $20-957$ & $\begin{array}{l}\text { N-903 Alternative failure probability calculation for a graphite core component Sec } \\
\text { III Div 5, Subsection } \mathrm{HH} \text {, subpart A. }\end{array}$ & Approved \\
\hline $19-2805$ & $20-954$ & Eliminate use of fluence and historical dose units and replace with dpa. & SC Approved \\
\hline $19-2806$ & new & $\begin{array}{l}\text { Correct Material Data sheets to explicitly require use of room temperature data } \\
\text { for strength }\end{array}$ & $\begin{array}{l}\text { Due NDM } \\
\text { review }\end{array}$ \\
\hline 20-1308 & new & $\begin{array}{l}\text { Modify the Weibull analysis nomenclature and parameter definitions within } \\
\text { Subsection sections HHA-II-3100 and HHA-II-3300 and standardize with ASTM } \\
\text { standards for all Nonmetallic Material Core Components }\end{array}$ & $\begin{array}{l}\text { Due NDM } \\
\text { review }\end{array}$ \\
\hline $20-1306$ & new & Modify HHA 3143 Abrasion and Erosion to eliminate specific gas velocity value & $\begin{array}{l}\text { Due NDM } \\
\text { review }\end{array}$ \\
\hline
\end{tabular}




\section{CERAMIC COMPOSITES}

\subsection{DESIGN RULES FOR COMPOSITE COMPONENTS}

The design and construction rules for composite components and assemblies were published for the first time in the 2019 edition of the ASME BPV Code Sec III, Div 5, under subsection HH, subpart B, and the general requirements of Subsection HA, subpart B. This was a significant accomplishment after an undertaking of several years (at moderate effort), which was first proposed in 2008.

The ASME code for composite materials applied the simplified assessment, previously discussed, whereby the material strength is probabilistically determined, which is compared with the component stress limit assigned by the predefined structural reliability class.

Like those for graphite, the code sections for ceramic matrix composites (CMC) differ from the rules for metallic components, because the reliability of CMCs cannot be expressed as the absence of cracks, as in the case of metals. CMCs, such as $\mathrm{C}-\mathrm{C}$ or $\mathrm{SiC}-\mathrm{SiC}$ matrix composites, are brittle ceramic fiber materials with minute flaws. It was concluded by many $[18,19]$ that the density function that best defines the material reliability is a Weibull Distribution. Weibull hypothesized that the probability of failure in structural components is influenced not only by the magnitude of local stresses but also by the stressed volume. The application is most useful for materials in which the strength distribution differs in such a way that very small failure values can occur. The material strength is determined by means of a two-parameter Weibull distribution.

The actual (calculated) POF values are derived from the material strength distribution, which is statistically determined by undetectable microstructural defects/cracks/flaws/porosity. Ultimately, it is up to the designer to evaluate the effects of cracking of components and ensure that the components, and the assembly they make up, are damage-tolerant. No safety factor or margin of safety is used in the assessment of component stresses; instead, the CMC component must be evaluated to ensure that the assigned safety function is retained with expected cracks and flaws throughout its lifetime.

Composites core components, like graphite core components, develop stresses from mechanical loads and from interactions with the fast neutron flux in the reactor. The distributions of temperature and fast neutron fluence create thermal and radiation-induced strains, as well as variations in mechanical properties in the composite component. Because the material properties change with operating time, the designer must calculate and track stresses over the lifetime for the different environmental conditions. This design approach, which considers the operating environment in design in Sec III, applicable for nonmetallic core components, is an exception to most of the code.

The ASME makes the following statement regarding this approach: [1]

Except for Sections XI and XII, and with a few other exceptions, the rules do not, of practical necessity, reflect the likelihood and consequences of deterioration in service related to specific service fluids or external operating environments. In formulating the rules, the Committee considers the needs of users, manufacturers, and inspectors of components addressed by the Code. The objective of the rules is to afford reasonably 
certain protection of life and property, and to provide a margin for deterioration in service to give a reasonably long, safe period of usefulness.

In addition, environmental effects during operation - such as irradiation and chemical attack, salt infusion, fatigue, and slow crack growth of the material — are to be considered in the design. The design specification specifies the service levels, which relate to the service limits applicable and define the allowable POF and deformation or other design limits for each composite core component in the core assembly.

There are several conditions that contribute to the design loadings, but the designer is required to determine and specify the loadings; these include, at a minimum, the temperature distribution, fast flux distribution, design pressure distribution, and mechanical loadings on the components. The assessment of the composite core components must include consideration of the effects of chemical attack (both thermal and radiolytic), irradiation, abrasion and erosion, fatigue, creep, and slow crack growth.

Because of the considerable design flexibility in the architecture, structure, and properties for CMCs, the composite material would need to conform to the requirements of the materials specification/s in the construction specification developed by the designer. Each component will have a detailed specification for the loading conditions set out in the code.

Besides the physical and mechanical material properties required for design, the material specification incorporates the irradiation effects, which include

- dimensional change

- irradiation creep coefficient

- CTE

- tensile strength (ultimate and proportional limit values)

- elastic modulus

- thermal conductivity

For the evaluation of chemical conditions, the material specification also requires as a minimum

- tensile strength (ultimate and proportional limit values)

- elastic modulus (dynamic)

- thermal conductivity

The design rules do not make use of a theory for combining stresses. Instead, the design approach requires a comparison between the maximum stress (in the dominant failure mode) resulting from the loading of the component, and the stress (in the same mode) at failure of the material. Stress analysis is to be performed on unirradiated, irradiated and oxidized (the effect of chemical attack) composite core components. For the unirradiated core components, an elastic analysis needs to be performed without accounting for irradiation damage - with the exception of thermal conductivity, which is used for thermal stress prediction. Finally, for cases where the dose exceeds 0.001 dpa. i.e., an irradiated composite. For such a condition analysis of the irradiated composite core components, irradiation-induced property changes on the material and the development of stresses in the components shall be accounted for. For analysis of oxidized core components, the effect of chemical attack on the dimensions and the distribution of material properties in 
the components shall be considered. The designer is responsible for the accuracy and acceptability of the analysis methods used. The allowable stress values depend on the POF, which is derived from the structural reliability class of the composite core component and the service level of the load. The design strength values for a defined POF are retrieved from the MDS of the specific ceramic composite material. The allowable stress values for tensile stresses, compressive stresses, bending, and shear stresses are to be determined from the measured and defined material design strengths in tension, compression, bending, shear, or another failure mode, respectively.

\subsection{MANDATORY AND NON-MANDATORY APPENDICES}

The articles under Subsection HH Subpart B are supported with information provided in the Mandatory Appendices and Nonmandatory Appendices. The Mandatory Appendices contain requirements that must be followed in construction for components and assemblies described in Subsection HH subpart B. The Nonmandatory Appendices provide additional information or guidance when using Subsection HH, Subpart B.

The existing articles and appendices of HHB are as follows:

- HHB-1000 Introduction

- HHB-2000 Materials

- HHB-3000 Design

- HHB-4000 Machining and Installation

- HHB-5000 Examination

- HHB-6000 Testing

- HHB-8000 Nameplates, Stamping and Report

- Mandatory Appendix HHB-I Material Composite Specifications

- Mandatory Appendix HHB-II Requirements for the Preparation of a Material Data Sheet

- Mandatory Appendix HHB-III Requirements for Generation of Design Data for Ceramic Matrix Composites

- Nonmandatory Appendix HHB-A Classifications of Ceramic Matrix Composites for Nuclear Applications

- Nonmandatory Appendix HHB-B Composition, Structure, Manufacture, and Properties of Ceramic Matrix Composites

- Nonmandatory Appendix HHB-C Fracture and Damage Mechanisms in SiC-SiC CMCs

The existing Mandatory Appendices describe details that need to be applied for CMCs. Within this category two groups of materials are being considered: $\mathrm{C}-\mathrm{C}$ (carbon fiber with a carbon matrix) and $\mathrm{SiC}-\mathrm{SiC}$ ( $\mathrm{SiC}$ fiber and an SiC matrix). There are currently no industry-wide materials standards for composites because of the range of composition, fiber architecture, manufacture and properties of composites. For this reason, composite materials are used by design (tailored for application) and not used in design (as with other materials like metals). The code is process based and requires that the designer specify the composite material to be used and then generate the material data required for the design. 
The mechanical, thermal and physical properties of CMCs are complex. The complexity is largely a result of the interaction of the constituents (fiber, matrix, porosity) in terms of chemistry, phase composition, microstructure, properties, architecture, fiber-matrix interphase and the effect of fabrication on the constituent properties. The two code-defined composite materials, $\mathrm{C}-\mathrm{C}$ and $\mathrm{SiC}-\mathrm{SiC}$, although similar, have unique differences in strength and failure mechanisms. C-C is a composite material with strong fibers but a weak matrix, while $\mathrm{SiC}-\mathrm{SiC}$ is a composite material with strong fibers and a strong matrix but a weak interphase.

The general description of the composition, architecture, manufacture, and properties of the ceramic composites is discussed in Nonmandatory Appendix HHB-B. However, the emphasis is largely focused on the properties and behavior of $\mathrm{SiC}-\mathrm{SiC}$ materials. Also, only the failure and damage mechanisms of $\mathrm{SiC}$ $\mathrm{SiC}$ are currently provided as guidance for material considerations. The code currently lacks discussion of $\mathrm{C}-\mathrm{C}$ specific properties and behavior or discussion of failure and damage mechanisms of C-C composite materials.

CMCs have been explored as higher-performance HTR materials in a relatively modest effort for several years, since the Pebble Bed Modular Reactor program first suggested C-C composites for the application of reflector tie rods and lateral restraint straps in the reactor core. This was followed by the requirement for C-C composite components such as control rod structural elements, upper vessel insulation support structure, and insulation shroud covers for the Next-Generation Nuclear Plant. [20.21]

C-C composites were identified as good materials for an accident situation and as having more industrial experience than $\mathrm{SiC}-\mathrm{SiC}$. However, its radiation damage resistance is lower than that of $\mathrm{SiC}-\mathrm{SiC}$, [21] but the damage tolerance requirement depends on the design application. The potentially life-limiting factors for CMCs are irradiation and oxidation (or chemical attack) effects, as well as long-term stress states (i.e. creep, slow crack growth, stress rupture).

C-C composites were previously considered for nonstructural applications in fusion systems as plasmafacing components because of their combination of toughness and high thermal conductivity. Low-level irradiation effects were studied. [22-24]

A task team within the NDM working group has started to develop drafts to amend the Nonmandatory Appendices to include $\mathrm{C}-\mathrm{C}$ specific material properties and environmental guidance.

\subsection{BACKGROUND OF C-C COMPOSITE MATERIALS}

Key requirements to consider for HTR core structural materials such as CMCs (classified as very or ultrahigh temperature materials), are change in thermal conductivity, melting or decomposition temperatures and neutron absorption (for sufficient fission reaction).[25] Carbon is an attractive core material because of its ability to moderate, or slow down, neutrons to speeds desirable for the uranium fission reaction. As explained in Mandatory Appendix HHB-II, CMC's can be divided into two groups, a weak matrix ceramic composite, where the load is mostly carried by fibers, and a weak interface ceramic composite, with a quasiductile toughness where the load is initially carried by both matrix and fibers. C-C is an example of a weak matrix composite with a strong, high modulus fiber in a low strength, low modulus matrix. 
C-C composite [26-29] materials are a class of high-temperature materials that consist of a carbon or graphite matrix, reinforced with carbon or graphite fibers. They can exhibit many of the high-temperature properties of graphite, such as low CTE and high thermal conductivity, but frequently additionally offer higher elastic modulus and strength. Perhaps their most attractive characteristic is their tailorability, where the properties in each direction are a function of the specified architecture and processing.

Previous studies of irradiated C-C materials were largely driven by fusion research, in which C-C composites were considered for their attributes such as high thermal shock resistance, lack of a melting temperature (similar to graphite), high thermal conductivity, low atomic number, and low neutron activation. [22,23] Both fusion and fission reactors considered CMCs for their ability to withstand extreme states that combine high radiation fluxes, elevated temperatures, and aggressive environments. Compared with graphite, C-C composites possess enhanced strength and low thermal expansion [30]; and historically, carbon-fiber composites had an industrial advantage over $\mathrm{SiC}$ composites because they were a more commercially mature product. This section provides background information for $\mathrm{C}-\mathrm{C}$ composites, as CMCs, for HTR application.

\subsubsection{Manufacture}

A typical C-C composite manufacturing process is illustrated in the flow diagram in Figure 4.

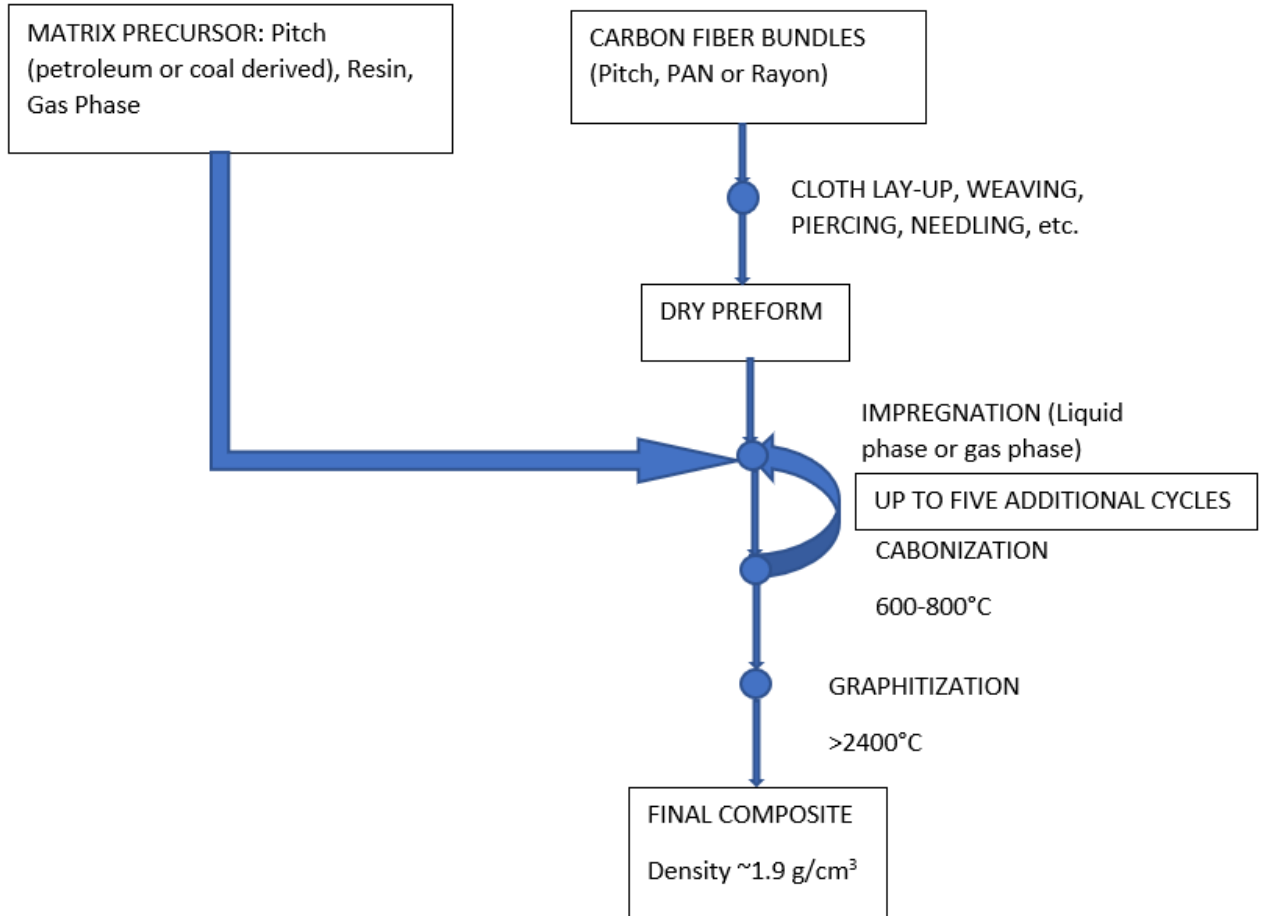

Figure 4. Flow diagram for a typical C-C composite production process 
The fiber [31] (liquid-precursor) choices available to the designer include rayon, polyacrylonitrile (PAN), and petroleum pitch-derived carbon fibers. The fiber precursor could also be gas-phase, e.g., vapor-grown carbon fibers [32]; but typically, gas-phase carbon fibers are discontinuous.

Extruded pitch filaments [33] or "spun" PAN filaments [33] are bought together (often by twisting) to form a tow or yarn bundle, which can be further processed if desired. The tow or yarn bundle may consist of several thousand filaments. The yarn is then in a condition where it can be further worked to produce a woven sheet (e.g., plain, satin) or braid, or laid up in a more complex multidirectionally reinforced preform. "Architecture" is a term used in the composites industry to describe yarn bundle size, filament count, and yarn bundle orientation or the filler fraction.

The preform is described as a unidirectional or 1-directional (1D), two-directional (2D), 3-directional (3D), 4-directional (4D), or even 5-directional (5D) composite depending upon the orientation of the reinforcing fibers. [26,34] A 2D stack can be "needled," which involves the repetitive driving of a needle through the cloth lay-up (perpendicular to the $\mathrm{x}$-y fiber direction) to force some of the fiber out of the plane into the $\mathrm{z}$ direction, thus yielding a pseudo-3D composite. Such materials are often referred to as being $2.5 \mathrm{D}$ architectures.

The details of the architecture need to be carefully specified to ensure the fibers are appropriately aligned to the stresses. A classification scheme for C-C composite structures has been devised (HHB-A) and ASTM C1836 [35], and this scheme should be used in conjunction with ASTM Standard Guide C1783 [36] (HHBA) and an appropriate specification developed (HHB-I).

Once a preform has been produced, it is densified by pressure impregnation with a liquid or gaseous carbon precursor to minimize the open (to the surface) porosity, followed by carbonization or pyrolysis. Achieving the desired density often requires multiple densification cycles. Moreover, it is not uncommon to have an intermediate machining step to remove any high-density skin formed around the product that might inhibit further impregnants from fully penetrating the product. In certain instances, the impregnation and carbonization steps may be replaced with a hot-pressing step.

Densification [27] in the gas phase usually involves some type of chemical vapor infiltration (CVI) process in which a carbon-rich precursor gas, such as methane, is passed through the preform at between $800^{\circ} \mathrm{C}$ and $1200^{\circ} \mathrm{C}$; the gas "cracks" and carbon in deposited. Often the process is conducted in conjunction with a gradient in temperature or pressure to enhance the resultant properties or reduce the process time. The exact morphology, density, and properties of the deposited carbon are controlled through process variables such as precursor gas (carbon yield), deposition rate, process temperature, and pressure.

A liquid-phase impregnant is a pitch or resin primarily selected to have a high carbon yield, although there are several other factors that influence the selection of an impregnant, such as the amount of pyrolysis shrinkage, the cost and availability (from multiple sources), and low solvent content.

The final step in processing a C-C composite is the graphitization step (if required), which usually takes place at a temperature $>2400^{\circ} \mathrm{C}$. It should be noted, however, that the final composite may not become graphite despite being "graphitized," as certain constituents may never go through the "mesophase stage" 
and thus thermally convert to graphite. In many instances, however, the final heat treatment temperature will control the properties of the $\mathrm{C}$-C composite, with an improvement in properties as the temperature of the final heat treatment increases.

Since there are so many variables in the formulation and processing of a $\mathrm{C}-\mathrm{C}$ composite it is imperative that the material be properly classified [35] (HHB-A) and completely specified [36] (HHB-I).

\subsubsection{C-C Properties}

Typical properties are difficult to define for a carbon composite material since there are so many variables in the manufacturing process (Figure 4). Indeed, the selection of the fiber type, pre-form architecture, matrix type, number of impregnation cycles, and final heat treatment temperature, all of which influence the properties, is usually application specific. Table 5 lists selected properties of several commercially available C-C composite materials.

C-C composites are often chosen because they offer (in addition to their high-temperature capabilities) a unique property or combination of properties. For example, the CTE (Table 5) is particularly low in C-C composites, which take advantage of the essentially zero axial CTE of carbon fibers.

Moreover, depending on how the material is specified, C-C composites can offer extraordinarily high strength and elastic modulus. It is reported in C-Cs and Their Industrial Applications [29] that a 1D C-C (unidirectional) composite made from HT (high-strength fibers) exhibited a tensile strength of $1100 \mathrm{MPa}$, a tensile modulus of $250 \mathrm{GPa}$, and strain-to-failure rate of $0.55 \%$ The flexure strength was reported to be $1200 \mathrm{MPa}$ and the flexural modulus to be $220 \mathrm{GPa}$. A 1D C-C composite made from HM (high-modulus) carbon fibers was reported [29] to exhibit a tensile strength of $700 \mathrm{MPa}$, a tensile modulus of $480 \mathrm{GPa}$, and a strain-to-failure of $0.15 \%$ The flexure strength was reported to be $600 \mathrm{MPa}$ and the flexural modulus $480 \mathrm{GPa}$.

The high thermal conductivity of C-C composite is an attractive property. The thermal conductivity in each direction is mostly influenced by the fiber (e.g., type, architecture) and can be estimated (in the fiber direction) by a mixtures law. [29] Since the thermal properties are largely controlled by the carbon fiber type, selection of the correct fiber type becomes particularly important. Generally, the higher conductivities [31] are ascribed to the HM type pitch-derived carbon fibers, followed by the HM PAN-derived carbon fibers. Rayon-derived carbon fibers have the lowest thermal conductivity. The select fiber type should be part of the materials specification. [36]

In instances where the fiber content is low in a specific direction, the contribution of the matrix to the property may become significant. Thus, proper specification of the matrix precursor and processing variables is particularly important [36] (HHB-I). 
Table 5: Selected properties of several commercially available C-C Composite materials. (adapted from [29])

\begin{tabular}{|c|c|c|c|c|c|}
\hline \multirow[b]{2}{*}{ Material constituents (if known) } & \multirow[b]{2}{*}{$\begin{array}{c}\text { Manufacturer/ } \\
\text { material ID }\end{array}$} & \multicolumn{4}{|c|}{ Physical properties } \\
\hline & & $\begin{array}{c}\text { Bulk } \\
\text { density } \\
\left(\mathrm{g} / \mathrm{cm}^{3}\right)\end{array}$ & $\begin{array}{c}\text { Young's } \\
\text { modulus, } \\
(\text { GPa) }\end{array}$ & CTE $\left(10^{-6} / \mathrm{K}\right)$ & $\begin{array}{c}\text { Thermal } \\
\text { conductivity } \\
(\mathrm{W} /(\mathrm{m}-\mathrm{K}))\end{array}$ \\
\hline \multicolumn{6}{|l|}{ 2D } \\
\hline Carbonized PAN cloth/ $\mathrm{C}_{\mathrm{CVI}}$ & Dunlop DMS 678 & 1.72 & & $0.69 *$ & $110^{x-y}, 23^{z}$ \\
\hline Carbonized PAN cloth/ $\mathrm{C}_{\mathrm{CVI}}$ & Schunk CF222 & 1.55 & 80 & $0.8^{\mathrm{x}, \mathrm{y}}, 7^{\mathrm{z}}$ & $40^{x-y}, 10^{z}$ \\
\hline Carbonized PAN cloth/C & Toyo Tanso CX76 & 1.51 & & $0^{\mathrm{x}, \mathrm{y}}, 8.4^{\mathrm{z}}$ & $40^{x-y}, 9^{z}$ \\
\hline Carbonized PAN Felt/ $\mathrm{C}_{\mathrm{CVI}}$ & $\begin{array}{l}\text { Toyo Tanso } \\
\text { CX2002U } \\
\end{array}$ & 1.65 & $11^{\mathrm{x}}, 8.1^{\mathrm{y}}, 3.4^{\mathrm{z}}$ & $1.7^{\mathrm{x}}, 2.3^{\mathrm{y}}, 5.3^{\mathrm{z} *}$ & $390^{\mathrm{x}}, 320^{\mathrm{y}}, 190^{\mathrm{z}}$ \\
\hline Felt $/ \mathrm{C}_{\text {Resin }}$ & ABS (B767 Brake) & & & $2.88(1173 \mathrm{~K})$ & $66^{x-y}, 13^{z}$ \\
\hline \multicolumn{6}{|l|}{ 2.5D (needled $\mathrm{z})$} \\
\hline $\begin{array}{l}\text { Carbonized PAN/ }\left(\mathrm{C}_{\mathrm{CVI}}+\right. \\
\text { H.P.Pitch) }\end{array}$ & SEP N112 & 2.01 & & $0.55^{*}$ & $166^{x-y}, 220^{z}$ \\
\hline Carbonized PAN/C $\mathrm{C}_{\mathrm{CVI}}$ & SEP N11 & 1.79 & & $1.34 *$ & $248^{z}$ \\
\hline P55(z,27\%) PAN (4\%)/C CVI & SEP NB31 & 1.9 & $15^{\mathrm{x}}, 12^{\mathrm{y}}, 107^{\mathrm{z}}$ & $1^{\mathrm{x}}, 2.1^{\mathrm{y}}, 0.4^{\mathrm{z}}$ & $117^{\mathrm{x}-\mathrm{y}}, 323^{\mathrm{z}}$ \\
\hline $\mathrm{P} 130 / \mathrm{C}_{\text {Pitch }}$ & FMI A27-130 & 2.03 & & $1.17^{*}$ & $309^{z}$ \\
\hline \multicolumn{6}{|l|}{ 3D } \\
\hline Granroc $(\mathrm{z}, 43 \% \mathrm{x}, 18 \% \mathrm{y}, 6 \%) / \mathrm{C}$ & Nisseki NIC-0I & & & $0.6^{\mathrm{x}}, 0.9^{\mathrm{y}},-0.6^{\mathrm{z}}$ & $537^{z}$ \\
\hline Rayon $(\mathrm{z}, 28 \% ; \mathrm{x}=\mathrm{y}=8.1 \%) / \mathrm{C}$ & DRDL & 1.8 & $25^{\mathrm{x}-\mathrm{y}}, 89^{\mathrm{z}}$ & & $130^{\mathrm{x}-\mathrm{y}}, 148^{\mathrm{z}}$ \\
\hline \multicolumn{6}{|l|}{ 4D } \\
\hline $\begin{array}{l}\text { Carbonized PAN }(\mathrm{z}, 14 \% \\
\mathrm{u}=\mathrm{v}=\mathrm{W}=8 \%) / \mathrm{C}\end{array}$ & DRDL & 1.8 & $31^{\mathrm{u}, \mathrm{v}, \mathrm{w}}, 38^{\mathrm{z}}$ & & $54^{\mathrm{u}, \mathrm{v}, \mathrm{w}}, 70^{\mathrm{z}}$ \\
\hline
\end{tabular}

* Average linear CTE 293-1273 K: x-longitudinal direction; y-cross direction, z-perpendicular direction 


\subsubsection{Irradiation Induced Damage}

As discussed in HHB-B-1530 [37], the irradiation effects on CMCs occur as a result of the irradiationinduced effects on the constituent materials. Accumulation of radiation-produced defects, in isolated, clustered, or extended forms, alters macroscopic properties of materials. Some effects of radiation in ceramics include volumetric swelling, anisotropic deformation, irradiation creep, thermal conductivity degradation, and various changes in mechanical properties.

In $\mathrm{CMCs}$, the macroscopic physical properties, such as dimensions and thermal conductivity, may evolve under radiation following constitutive laws regarding mechanical integrity. However, the radiation effects on mechanical properties are not simple because of the complex interplay among mechanical property changes of fiber, matrix, and interphase; differential deformation; anisotropy effects and mechanical constraints specific to the material system; and fiber architecture. [37]

The carbon atoms of the fibers and matrix are arranged in a hexagonal graphite crystal structure; and as in graphite, the neutron damage $(\mathrm{E}>0.1 \mathrm{MeV})$ induces dimensional changes in both fiber and matrix. During irradiation, carbon atoms may be displaced. Those that do not recombine may remain as interstitial atoms and perhaps come to rest as interstitial complexes (Figure 5 [24]) between planes in the c-axis (weakly bonded through van der Waals forces). Defects are formed as a result of the mobility of the interstitial atoms and intraplane vacancies that cause c-axis swelling and a-axis shrinkage in an approximately volumeconserving fashion as confirmed by results reported in [38] (data points marked by red circles in Figure 6). The dimensional changes depend on the temperature and fluence conditions. Additionally, the formation of neutron irradiation-induced defect structures in the graphite lattice (which are temperature-dose dependent), affects the physical properties of C-C composites negatively. Because of the microstructural changes in an irradiated material, the thermal conductivity decreases (because of additional thermal resistance from scattered phonons), the electrical resistivity increases (because of scattered electrons), and the strength and the elastic moduli increase (because of pinning of dislocation lines). [24,39]

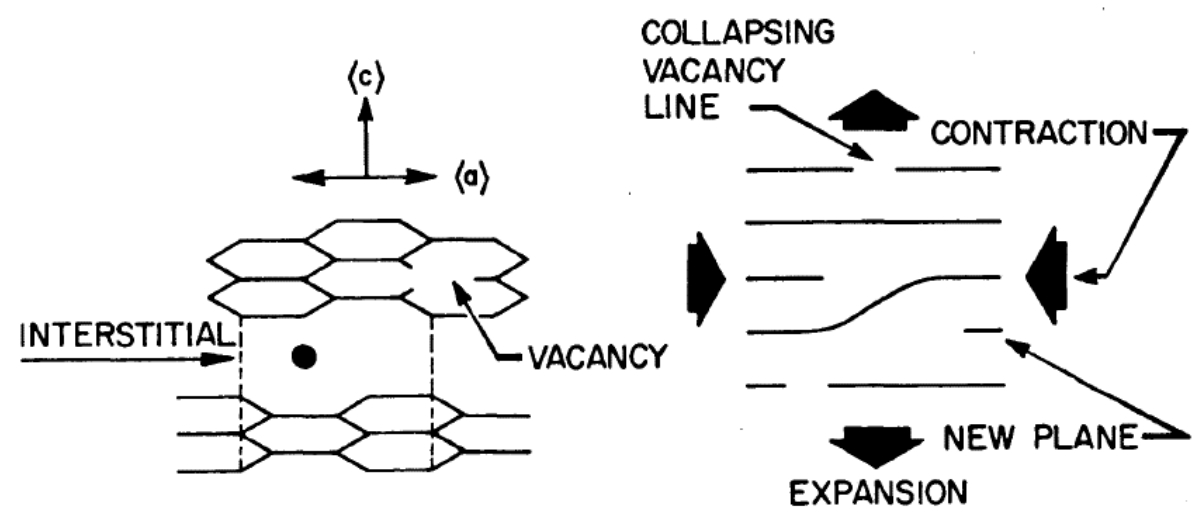

Figure 5. The mechanism of radiation damage in the graphite crystal (adopted from [24]) 


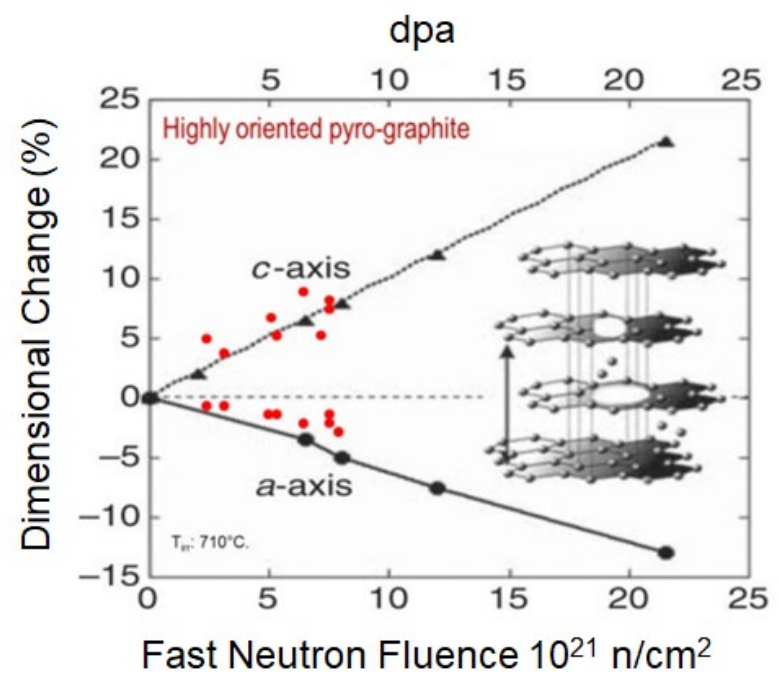

Figure 6. Irradiation-induced anisotropic dimension change in a HOPG crystal (adapted from [38])

\subsubsection{Irradiation Induced Dimensional Changes}

Carbon-fiber composites are susceptible to irradiation induced degradation due to anisotropic dimensional changes. The nature and complexity of the composite architecture (fibers, preform/fiber architecture, interfacial coating, matrix) influence its irradiation performance. The existence of shrinkage porosity (voids) between the layers (Figure 7) will interact with the c-axis growth.

Carbon-composites, like graphite, saturate at some irradiation temperature and dose, known as "turnaround". The useful lifetime of the material is up to "crossover," or the point where the swelling returns to zero. It is assumed that the macroscopic behavior in C-C composites, as a result of anisotropic swelling, is dominated by the fibers. Figure 7 illustrates the PAN carbon fiber structure, showing the crystallographic $<\mathrm{a}>$ and $<\mathrm{c}>$ directions in the sheath directions. [22] The carbon fibers will initially shrink diametrically and in length; then, when it reaches turnaround (interplanar porosity filled), it will swell diametrically while it continues to shrink in length.

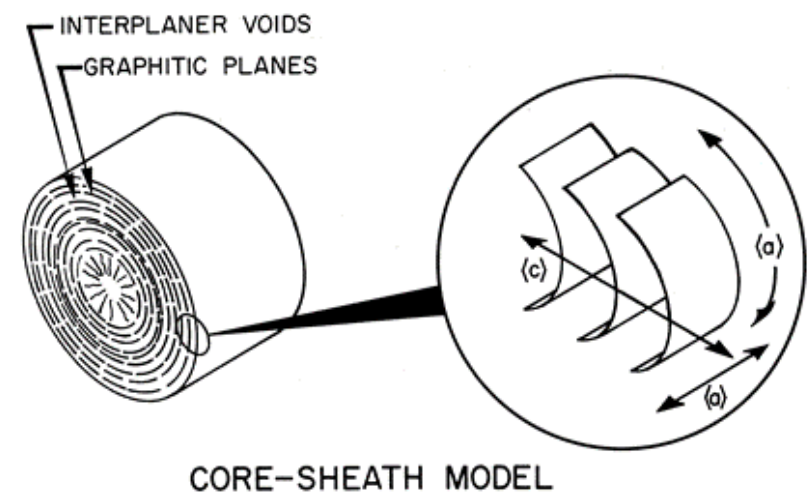

Figure 7. The core-sheath model of PAN derived carbon fiber structure. [22] 
Fiber bundles can be 1D or multi-directional (2D, 3D, etc.). It is shown [22] that 3D C-C composites exhibit more isotropic dimensional changes than 1D or even 2D composites. Figure 8 [23] shows the irradiationinduced dimensional effect of cylindrical specimens irradiated at $600{ }^{\circ} \mathrm{C}$ in a $1 \mathrm{D}$ fiber C-C composite (or 1D UFC) from PAN, or 2D PAN fiber - chopped (or a 2D RFC), and a 3D PAN or 3D C-C composite with PAN fibers (irradiated up to $\sim 4.5 \mathrm{dpa}$ ).

The 1D and 2D C-C composites first shrank in diameter up to 1dpa and then started to swell, while the 3D C-C composite behaved isotropically, shrinking up to 2 dpa when diametrical turnaround was reached.

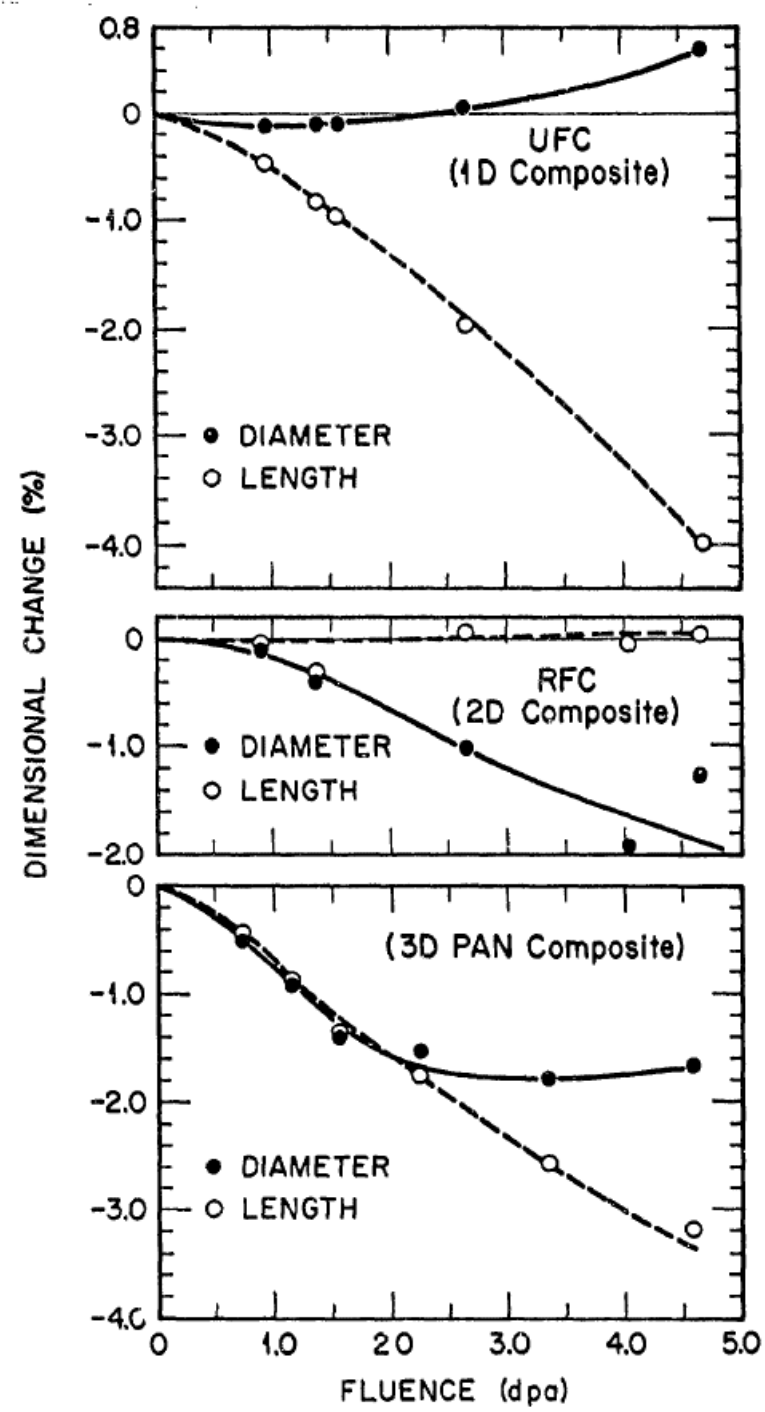

Figure 8. Neutron irradiation induced dimensional changes of several C-C composites irradiated at $600^{\circ} \mathrm{C} .[23]$

Figure 9 shows the dimensional change comparison between pitch-based fibers and PAN fibers [40]. Pitch-based fiber composites are more dimensionally stable than the PAN fiber C-C composites. 


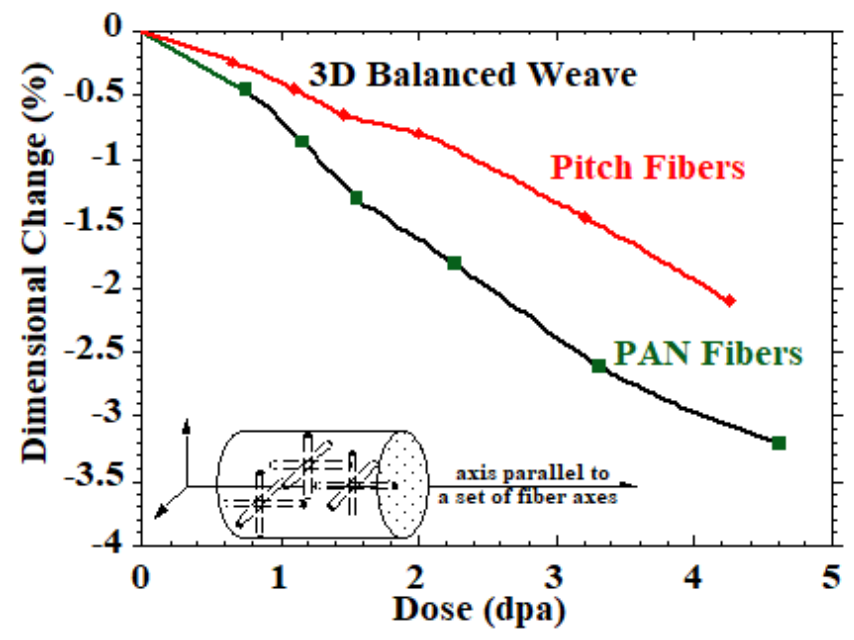

Figure 9. Irradiation dimensional change in two 3D, C-C composites; pitch and PAN fibers [40]

$\mathrm{C}-\mathrm{C}$ has moderate radiation damage resistance. Degradation of a 3D C-C structure following neutron irradiation was reported [42] at a dose of $10 \mathrm{dpa}$ with serious structural disintegration at $800^{\circ} \mathrm{C}$. Figure 10 shows a 3D, well balanced, pitch-based fiber weave composite that demonstrated anisotropic behavior after exposure to a temperature and fast fluence of $500^{\circ} \mathrm{C}$ and $6 \times 10^{25} \mathrm{n} / \mathrm{m}^{2}(\mathrm{E}>0.1 \mathrm{MeV})$ and $800^{\circ} \mathrm{C}$ and $7.7 \times 10^{25}$ $\mathrm{n} / \mathrm{m}^{2}(\mathrm{E}>0.1 \mathrm{MeV})$. [40,41] It shows serious degradations and anisotropic dimensional change in the form of swelling and shrinkage of fiber bundles. Snead [41] explained that the specimen in the $800^{\circ} \mathrm{C}$ condition, had undergone significantly higher shrinkage, causing gaps (bundles have shrunk away from the surface, the matrix swells and fiber bundles grow radially).
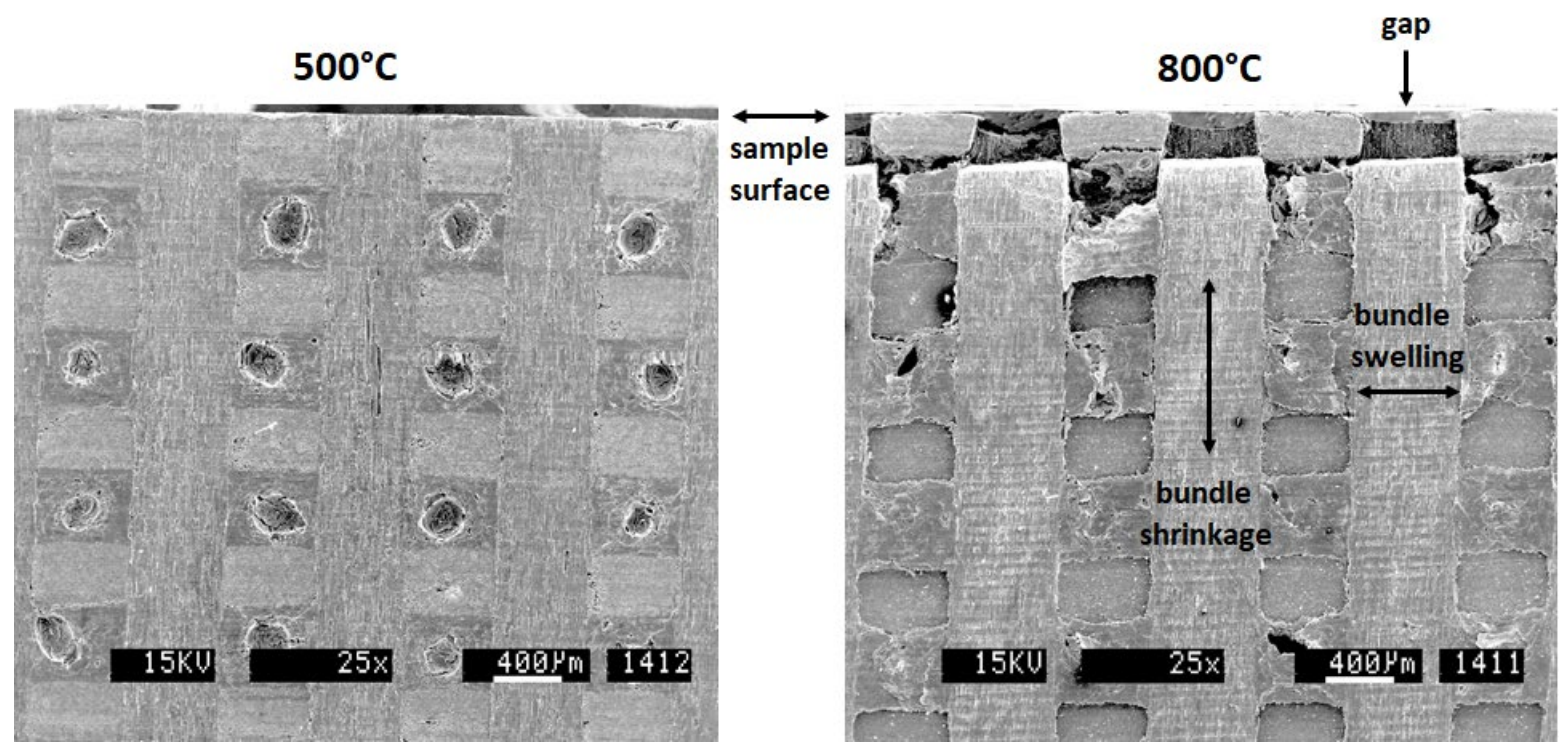

Figure 10. C-C composite following irradiation (at $500^{\circ} \mathrm{C}$ and $800^{\circ} \mathrm{C}$ ) (From [40]) 


\subsubsection{Irradiation Induced Changes in Physical Properties}

Degradation of thermal conductivity due to neutron damage will result in higher operating temperatures. Previously irradiated (fluence range 1 to $4.5 \mathrm{dpa}$ ), 3D PAN fiber (FMI 223) and 3D pitch fiber (FMI 222) materials have been compared and display similar trends as shown in Figure 11 [23]. Both C-C composites suffer severe irradiation degradation of thermal conductivity. Figure 12 [23] demonstrates a reduction of between 50 and $60 \%$ at an irradiation temperature of $600^{\circ} \mathrm{C}$.
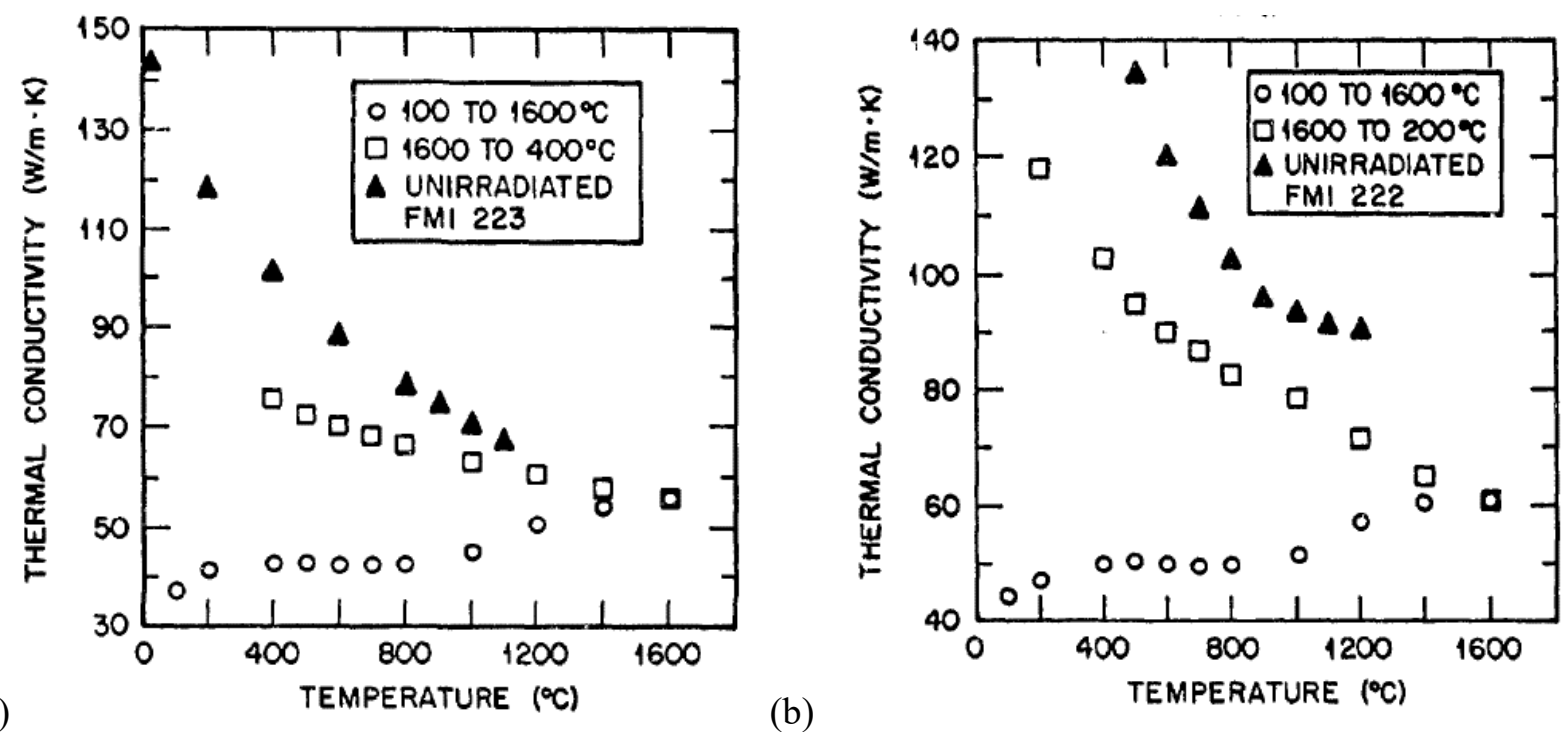

Figure 11. Temperature dependence of thermal conductivity for 3D C-C composites (a) PAN fiber and (b) pitch-based fiber [23]

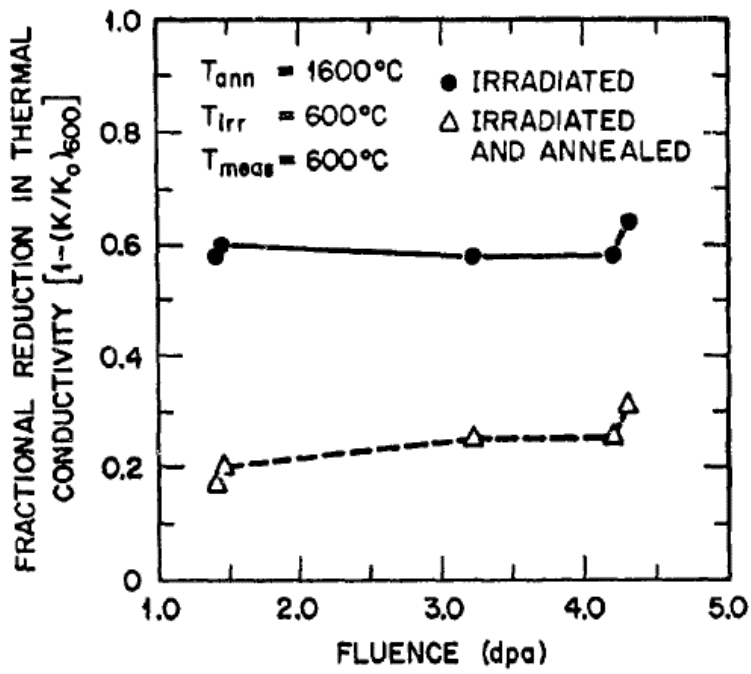

Figure 12. Fractional reduction in thermal conductivity as a function of neutron irradiation. [23]

As in the case of graphite, it has also previously been suggested that there is a dramatic drop in thermal conductivity at very low irradiation conditions $\left(0.01 \mathrm{dpa}\right.$ and $\left.200^{\circ} \mathrm{C}\right)[30,42]$ 


\subsubsection{Irradiation Induced Changes in Mechanical Properties}

Carbon-composites, like graphite, saturate volume changes at "turnaround". This is when the irradiated material behavior changes from densification to swelling leading to strain-induced cracks and severe degradation in material strength. At a low irradiation dose, $\mathrm{C}-\mathrm{C}$ composites experience increased strength and fracture toughness. [22]

From previous irradiation studies in which C-C was investigated for a plasma-facing first wall material in fusion reactors, several mechanical properties pre- and post-irradiation were reported and are provided in Table 6. Three C-C composite materials were reported. C-C-A is a pitch fiber composite (with a coal tar binder) and C-C-B is a PAN fiber composite. The 2D-C-C is claimed to be a two-dimensional cloth layered Rayon carbon fiber composite. [43] The pitch fiber composites presented the greatest strength gains.

Table 6: Mechanical properties of three C-C composites materials - post irradiation comparison (adapted from [43])

\begin{tabular}{|l|c|c|c|c|c|c|c|}
\hline & & \multicolumn{2}{|c|}{ C-C-A } & \multicolumn{2}{c|}{ C/-C-B } & \multicolumn{2}{c|}{ 2D-C-C } \\
\hline & Units & Pre Irr. & Post Irr. & Pre Irr. & Post Irr. & Pre Irr. & Post Irr. \\
\hline Irradiation Temperature & ${ }^{\circ} \mathrm{C}$ & - & $750-810$ & - & $750-810$ & - & $650-710$ \\
\hline $\begin{array}{l}\text { Total neutron fluence }\left(\mathrm{x} 10^{21}, \mathrm{E}>\right. \\
0.181 \mathrm{MeV})\end{array}$ & $\mathrm{n} / \mathrm{cm}^{2}$ & - & 1.2 & - & 1.2 & - & $1.75-1.88$ \\
\hline Dose $(\mathrm{E}>0.18 \mathrm{MeV})$ & $\mathrm{dpa}$ & & 1.07 & & 1.07 & & $1.56-1.67$ \\
\hline Young's Modulus, $\mathrm{E}$ & $\mathrm{GPa}$ & 13.5 & 19.2 & 26.3 & 34.2 & 23.8 & 31.6 \\
\hline Compressive Strength, $\sigma_{\mathrm{t}}$ & $\mathrm{MPa}$ & 44.9 & 58.4 & 66.6 & 81.2 & - & - \\
\hline Bending strength, $\sigma_{\mathrm{b}}(\mathrm{ll})$ & $\mathrm{MPa}$ & 65.7 & 81.5 & 96.6 & 119.2 & 117 & 145 \\
\hline Bending strength, $\sigma_{\mathrm{b}}(\perp)$ & $\mathrm{MPa}$ & 57.4 & 79.8 & 94.5 & 110 & 116 & 143 \\
\hline Tensile strength, $\sigma_{\mathrm{t}}$ & $\mathrm{MPa}$ & 35.7 & - & 55.4 & - & 90.1 & 114 \\
\hline Critical Stress Intensity Factor, $\mathrm{K}_{\mathrm{Ic}}$ & $\mathrm{MPa} \cdot \mathrm{m}^{1 / 2}$ & 2.96 & 3.65 & 3.44 & 4.14 & 5.26 & 5.77 \\
\hline Critical Stress Intensity Factor, $\mathrm{K}_{\mathrm{Ic}}$ & $\mathrm{MPa} \cdot \mathrm{m}^{1 / 2}$ & 2.14 & 2.65 & 3.03 & 3.94 & - & - \\
\hline Critical Stress Intensity Factor, $\mathrm{K}_{\mathrm{Ic}}$ & $\mathrm{MPa} \cdot \mathrm{m}^{1 / 2}$ & 3.79 & 4.85 & 4.39 & 5.56 & - & - \\
\hline
\end{tabular}

\subsubsection{Effects of Chemical Attack/Oxidation on C/C Composites}

As discussed in Nonmandatory Appendix HHB-B, the corrosion response of CMCs is strongly affected by the degree of degradation of the properties of the constituents, i.e., the fibers and matrix. In general, ceramic materials are very resistant to corrosion. However, the broad spectrum of manufacturing techniques with different sintering additives, mixtures, glass phases, and porosities is crucial to determining the degree of corrosion in CMCs. Fewer impurities and exact stoichiometry lead to less corrosion.

The application of C-C composites started with rocket nozzle and re-entry parts for military or space projects. They have since been widely used for brakes in the civil aircraft industry. [29] Mechanical and thermal properties are affected by long term oxidation. With oxidation new pores are generated in the structure and the bulk density decreases. This is demonstrated by Liu et al [44], where two pitch-matrix 2D $\mathrm{C}-\mathrm{C}$ composites (material 1 and material 2) were used in an oxidation experiment. The two materials were 
produced from carbon cloth (x-y direction) pierced by fibers (z-direction) and had a carbonized pitch matrix. The carbon fiber diameter for materials 1 and 2 were 1.2 and $1.4 \mathrm{~mm}$ respectively. Material 1 has a tensile strength of 45.5 and 100.5 MPa in the x-y- and z-direction respectively, with a Young's modulus of 32.6 and $10.6 \mathrm{GPa}$ in the $\mathrm{x}-\mathrm{y}$ - and z-direction respectively. Material 2 has a reported tensile strength of 146.7 and $132.7 \mathrm{MPa}$ in the $\mathrm{x}-\mathrm{y}$ - and z-direction respectively, with a Young's modulus of 70.5 and $53.3 \mathrm{GPa}$ in the $x-y-$ and $z$-direction respectively. The two carbon composite materials exhibited different oxidation rates reflecting differences in their architecture.

Arrhenius equations can be used to define the oxidation rates of C-C composites. Burn-off effects were examined in several studies and are reported elsewhere [22,29,45]. Generally, it was found by air oxidation that Young's modulus, bend strength and fracture toughness values decrease with increasing burn-off.

\subsubsection{Potential Applications of Composites in HTRs}

Several potential applications of composites can be identified. [25,46] Some of the applications could be $\mathrm{SiC}-\mathrm{SiC}$ composites (HBB-B) rather than C-C composites. The components identified as potentially being suitable for composite material are all within the pressure vessel and are all low neutron dose (except potentially for the control rod housing application).

The low to no dose applications [46] included a core restraint strap that surrounds the graphite core and restrains the block and prevents loss of alignment when the graphite core goes through a thermal transient. The material selected for this application would require (1) adequate tensile strength, (2) retention of tensile properties to high temperature, and (3) a matched CTE to that of the graphite core assembly. The extremely low CTE of C-C composites is attractive, and a strap with composite links and metallic links can be designed to match the CTE of the reactor core.

Another potential (low-dose) composite application in a pebble-bed type graphite reactor would be for tie rods that support the graphite core blocks that make up the core top-reflector, suspending them from the reactor vessel head. The high tensile strength and the retention of tensile properties to elevated temperatures make $\mathrm{C}-\mathrm{C}$ composites attractive materials for tie-rods.

To offer thermal protection to the vessel top head during an off-normal core cool down a shroud could be used. The structural requirements of this thermal shroud assembly could be met with a composite material. Moreover, C-C composites would make excellent core outlet connections where their favorable hightemperature properties are attractive.

Composite materials are also being considered for control rod cladding and for control rod guide tubes. Depending upon the conditions of use (i.e., if the tip of the control rod is used for flux shaping) the control rod tip cladding would be subjected to a higher neutron flux and a SiC-SiC Composite may be better suited.

\subsection{COMPOSITE MATERIALS AND NRC ASSESSMENT REVIEW}

The current endorsement review performed by the NRC is limited to the 2017 edition of the ASME BPV Code Sec III, Div 5. This excludes the new addition of composites to general requirements under subsection $\mathrm{HA}$, subpart B and the design rules under subsection $\mathrm{HH}$, subpart B. However, it is foreseeable that once 
the code under Sec III Div 5 has been endorsed, it will follow that new or additional subsections (post-2017 edition) will require a similar review effort.

In this instance, subsection $\mathrm{HH}$, subpart $\mathrm{B}$, will require a technical basis to support the review. This has been identified as a potential gap. This need was confirmed in a workshop titled "Current use of graphite and future use of composites in HTR cores" during an ASME BPV Code NDM working group meeting in Salt Lake City, Utah, in 2019 with volunteers from national laboratories, vendors and the regulator. A task group will be established to address this action.

\subsection{RECORD AND BALLOT STATUS}

Table 7 summarizes the current status of action items for the NDM working group review.

Table 7: Records and Ballots relevant to HHB for working group review

\begin{tabular}{|l|c|l|c|}
\hline \#Record & $\begin{array}{c}\text { Last } \\
\text { \#Ballot }\end{array}$ & \multicolumn{1}{|c|}{ Purpose } & Status \\
\hline $17-2659$ & - & Editorial changes to consolidated HHB: Composites & Due for ballot \\
\hline $20-1307$ & - & $\begin{array}{l}\text { Include C-C composites in nonmandatory appendices (as part of CMC } \\
\text { material for HTR) }\end{array}$ & $\begin{array}{l}\text { Due working group } \\
\text { review }\end{array}$ \\
\hline
\end{tabular}




\section{SUMMARY}

This report summarizes the progress of ASME nonmetallic core component efforts that include graphite and composite materials. Significant effort was provided to support the NRC review activity for the endorsement of ASME BPV Code Sec, III Div 5. Two manuscripts will be provided to ASME that provide the background for the development of the graphite component and assembly design rules (Appendix A), as well as address the concerns regarding adequacy or further optimization needs. Other significant accomplishments include the first-time publication of the ceramic composite materials under Subsection $\mathrm{HH}$, subpart B and the approval of a new code case to determine the integration volume for the design of graphite components.

Several ongoing task group actions have been discussed for both graphite and composites. It is foreseen that it is possible to define irradiation performance trends for different graphite grades (up to turnaround) based on fabrication parameters. This effort can address and reduce the risk associated with needing to do large irradiation campaigns required for graphite qualification. Optimization of the Weibull parameters provided in the Mandatory Appendices HHA-II-3000 and HHB-II-3000 is needed. The optimization effort also include integration with ASTM D7846. Despite the identified applications for C-C composites, the code lacks further description, which is currently being addressed. A next step for the composite design rules is to develop a technical basis for their application in HTRs. 


\section{REFERENCES}

[1] ASME Boiler and Pressure Vessel Code, Section III, Div. 5, Foreword, American Society of Mechanical Engineers, Two Park Avenue, NY, 2019.

[2] D.K. Morton, R.I. Jetter, James E. Nestell, T.D. Burchell, T.L. (Sam) Sham, Section III, Division 5-Development and Future Directions, Proceedings of the ASME 2012 Pressure Vessels \& Piping Division Conference (PVP2012), Toronto, Ontario, Canada, July 15-19, 2012.

[3] L.L. Snead, Y. Katoh, W.E. Windes, R.J. Shinavski, T.D. Burchell, Ceramic composites for near term reactor application, in Proceedings of the 4th International Topical Meeting on High Temperature Reactor Technology -2008, vol. 2, American Society of Mechanical Engineers, New York, 2009, pp. 1-10.

[4] W. Corwin, Endorsement of ASME Section III Division 5 rules for construction of high temperature nuclear reactors: Update on industrial perspective, Nuclear Regulatory Commission Public Meeting, Rockville, MD, December 14, 2017.

[5] ASME Boiler and Pressure Vessel Code, Section III, Div. 5, American Society of Mechanical Engineers, Two Park Avenue, NY, 2017.

[6] R. Sowinski, Update on DOE consensus-based standards efforts, Nuclear Regulatory Commission Standards Forum, Rockville, MD, September 11, 2018.

[7] Nuclear Regulatory Commission, Summary of December 9-11, 2019, International Workshop on ANLWR - Materials and Component Integrity, ML20030B778, Rockville, MD, January 2020.

[8] M. Burke, D. Gandy, Material and properties development needs for design and development of commercially viable Gen IV reactors, presented at the International Workshop on Advanced Non-Light Water Reactors-Materials and Component Integrity, Rockville, MD, December 9$11,2019$.

[9] M.P. Hindley, M.N. Mitchell., C. Erasmus, R. McMurtry, T.H. Becker, D.C. Blaine, A.A. Groenwold, A numerical stress-based approach for predicting failure in NBG-18 nuclear graphite components with verification problems, JNM 436, 175-184, 2013.

[10] T. Burchell, ASME Graphite Code-Future developments, Advanced Materials R\&D Program Review, Idaho Falls, ID May 6-8, 2014.

[11] T.D. Burchell, D.L. Erdman III, R.R. Lowden, J.A. Hunter, C.C. Hannel, The Fracture Toughness of Nuclear Graphites Grades, ORNL/TM-2016/678, Oak Ridge National Laboratory, 2016.

[12] Bufo Technology, Graphite Failure Calculation Code Analysis Process Zone versus Grain Size, R109-003-01, Pretoria, South Africa.

[13] Nuclear Regulatory Commission, Graphite PIRTs, ORNL/TM-2007/147, vol. 5 of Next Generation Nuclear Plant Phenomena Identification and Ranking Tables, NUREG/CR-6944, US Nuclear Regulatory Commission, Rockville, MD, 2008

[14] R. Bratton, T.D. Burchell, AGC-1 Experiment and Final Preliminary Design Report, INL/EXT-05-00622, Rev. 2, Idaho National Laboratory, 2006.

[15] W. Windes, J.W. Geringer, ASME Nonmetallic Design and Materials Working Group Highlights, presented at ASME Code Week, Virtual Conference, May 11, 2020

[16] ASME Boiler and Pressure Vessel Code, Section III, Div. 5, HHA-II-3000, American Society of Mechanical Engineers, Two Park Avenue, NY, 2019.

[17] ASTM International, Standard Practice for Reporting Uniaxial Strength Data and Estimating Weibull Distribution Parameters for Advanced Graphites, D7846, Annual Book of ASTM Standards, ASTM International, West Conshohocken, PA, 2019.

[18] US Department of Transportation, Probabilistic Design Methodology for Composite Aircraft Structures, DOT/FAA/AR-99/2, Office of Aviation Research, Washington, DC, 1999. 
[19] Westinghouse Reaktor GmbH, Reliability Analysis of Graphite Structures Part II: Theoretical and Experimental Investigations, Report No. GBRA 050 308, Mannheim Germany, 2001.

[20] W.R. Corwin, et al., Updated Generation IV Reactors Integrated Materials Technology, Rev. 2, ORNL/TM-2005/556, Oak Ridge National Laboratory, 2005.

[21] W.R. Corwin, et al., Generation IV Reactors Integrated Materials Technology Program Plan: Focus on Very High Temperature Reactor Materials, ORNL/TM-2008/129, Oak Ridge National Laboratory, 2008.

[22] T.D. Burchell, Radiation damage in carbon-carbon composites: Structure and property effects, Physica Scripta 64, 17-25, 1996.

[23] T.D. Burchell., Irradiation-induced Structure and Property Changes in Tokamak Plasmafacing, Carbon-Carbon Composites, Moving Forward with 50 Years of Leadership in Advanced Materials, 39th International SAMPLE Symposium and Exhibition, vol. 39, Books 1 and 2, pp. 2423-2436, 1994.

[24] T.D. Burchell, T. Oku, Materials Properties Data for Fusion Reactor Plasma Facing CarbonCarbon Composites, International Atomic Energy Agency, pp. 77-128, 1994.

[25] C. Sauder, Ceramic Matrix Composites: Nuclear Applications, chapter 22 in Ceramic Matrix Composites: Material, Modelling and Technology, ed. N.P. Bansal, J. Lamon, John Wiley \& Sons, 2015.

[26] J.D. Buckley, D.D. Edie, eds., Carbon-Carbon Materials and Composites, ISBN 0-8155-13240, Noyes Publications, Norwich, NY, 1993.

[27] C.R. Thomas, ed., Essentials of Carbon-Carbon Composites, ISBN 0-85186-804-5, Royal Society of Chemistry, London, UK, 1993.

[28] R. Weiss, Carbon/Carbons and their Industrial Applications, chapter 4 in Ceramic Matrix Composites, ed. W. Krenkel, pp. 69-111, ISBN 978-3-527-31361-7, Wiley-VCH Verlag GmbH \& CI KGaA, Weinheim, Germany, 2008.

[29] H. Hatta, R. Weiss, P. David, Carbon/Carbons and their Industrial Applications, chapter 5 in Ceramic Matrix Composites: Materials, Modelling and Technology, ed. N.P. Bansal, J. Lamon, pp. 87-146, Jon Wiley \& Sons, 2015.

[30] N. Simos, Composite Materials under Extreme Radiation and Temperature Environments of the Next Generation Nuclear Reactors, chapter 28 in Metal, Ceramic and Polymeric Composites for Various Uses, ed. John Cuppoletti, InTech, 2011.

[31] J.-B. Donnet, R.C. Bansal, Carbon Fibers, Second Edition, Revised and Expanded, ISBN 08247-7865-0, Marcel Dekker, 1990.

[32] M. Lake, J.-M. Ting, Vapor Grown Carbon Fiber Composites, chapter 5 in Carbon Materials for Advanced Technologies, ed. T.D. Burchell, pp. 139-167, ISBN 0-08-042683-2, Elsevier Science, 1999.

[33] D.D. Edie, J.J. McHugh, High Performance Carbon Fibers, chapter 4 in Carbon Materials for Advanced Technologies, ed. T.D. Burchell, pp. 119-138, ISBN 0-08-042683-2, Elsevier Science, 1999.

[34] L. McAllister, Multidirectionally Reinforced Carbon/Graphite Matrix Composites, in Engineered Materials Handbook, vol. 1, Composites, pp. 915-919, ASM International, Metals Park, Ohio 44037 (1987).

[35] ASTM International, Standard Classification for Fiber Reinforced Carbon-Carbon Composite Structures, ASTM C1836, Annual Book of ASTM Standards, ASTM International, West Conshohocken, PA, 2016.

[36] ASTM International, Standard Guide for Development of Specifications for Fiber Reinforced Carbon-Carbon Composite Structures for Nuclear Applications, ASTM C1783, Annual Book of ASTM Standards, ASTM International, West Conshohocken, PA, 2015. 
[37] ASME Boiler and Pressure Vessel Code, Section III, Div. 5, HHB Nonmandatory Appendix B, American Society of Mechanical Engineers, Two Park Avenue, NY, 2019.

[38] N.C Gallego, C.I. Contescu, T.D. Burchell, XRD and SANS evaluation of HOPG and Polycrystalline Graphite, ORNL/TM-2018/871, Oak Ridge National Lab, 2018

[39] Irradiation Damage in Graphite Due to Fast Neutrons in Fission and Fusion Systems, IAEATECDOC-1154, International Atomic Energy Agency, September 2000.

[40] L. Snead, Ceramic structural composites: The most advanced structural material, presented at the International School on Fusion Reactor Technology, Erice, Italy, July 26-August 1, 2004.

[41] L.L. Snead, et al., Strength of neutron-irradiated high-quality 3D carbon fiber composite, JNM 321, 165-169, 2003.

[42] N. Maruyama, M. Harayama M., Neutron irradiation effect of thermal conductivity and dimensional change of graphite materials, JNM 195, 44-50, 1992.

[43] S. Sato, A. Kuramada, K. Kawamata, R. Ishida, Thermal shock resistances and fracture toughnesses of graphites and $\mathrm{C} / \mathrm{C}$-composites as plasma-facing first wall components for fusion reactor devices, Fusion Engineering and Design 13, 159-176, 1990.

[44] Liu, L.Y., Han, J.C., He, X.D., Wan, J., Extended Abstracts, 21st Biennial Conf. on Carbon June 13-18 (1993) 535-536.

[45] L.E Jones, P.A Thrower, Influence of boron on carbon fiber microstructure, physical properties, and oxidation behavior, Carbon 29(2), 251-269, 1991.

[46] Y. Katoh L.L. Snead, K. Ozawa, C. Contescu, T.D. Burchell, S. Gonczy, W.E. Windes, Carbon composite R\&D for high temperature gas-cooled reactors, presented at INGSM-11, Eastbourne England, September 12-15, 2010. 
APPENDIX A. 


\title{
Background Information for Addressing Adequacy or Optimization of ASME Section III, Division 5 (2017 ed.) Rules for Nonmetallic Core Components*
}

\author{
Prepared by \\ Josina W. Geringer ${ }^{1}$, Timothy D. Burchel1 ${ }^{1}$, Mark Mitchel1 ${ }^{2}$ \\ ${ }^{1}$ Oak Ridge National Laboratory \\ ${ }^{2}$ Ultra Safe Nuclear Corporation
}

June 2020

\footnotetext{
* This manuscript was prepared as an account of work sponsored by an agency of the United States Government. Neither the United States Government nor any agency thereof, nor any of their employees, makes any warranty, express or implied, or assumes any legal liability or responsibility for the accuracy, completeness, or usefulness of any information, apparatus, product, or process disclosed, or represents that its use would not infringe privately owned rights. Reference herein to any specific commercial product, process, or service by trade name, trademark, manufacturer, or otherwise, does not necessarily constitute or imply its endorsement, recommendation, or favoring by the United States Government or any agency thereof. The views and opinions of authors expressed herein do not necessarily state or reflect those of the United States Government or any agency thereof.
} 